NASA Technical Memorandum 87281

AIAA-86-1703

\title{
NASA Electrothermal Auxiliary Propulsion Technology
}

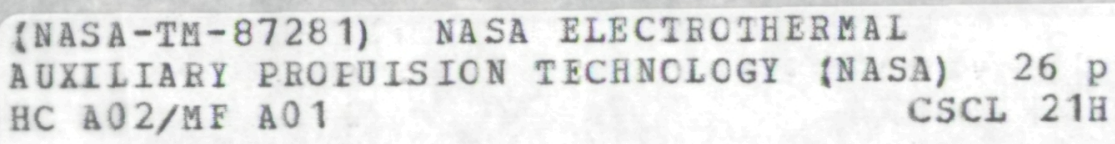

James R. Stone

Lewis Research Center

Cleveland, Ohio

Prepared for the

22nd Joint Propulsion Conference

cosponsored by the AIAA, ASME, SAE, and ASEE

Huntsville, Alabama, June 16-18, 1986

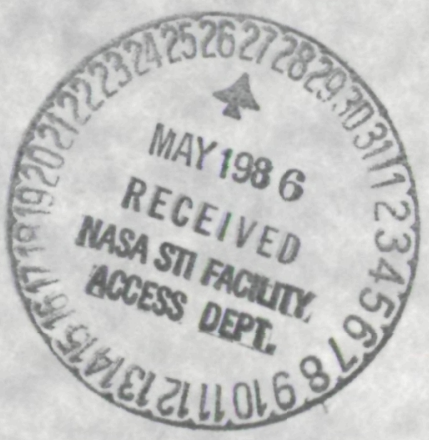


NASA ELECTROTHERMAL AUXILIARY PROPULSION TECHNOLOGY

James R. Stone

National Aeronautics and Space Administration

Lewis Research Center

Cleveland, Ohio 44135

\section{Abstract}

Electrothermal auxiliary propulsion systems provide high performance options which can have major mission benefits. There are several electrothermal concepts which offer a range of characteristics and benefits. Resistojets are the highest thrust-to-power option and are currently operational at mission average values of specific impulse, $I_{\text {sp }} \approx 295 \mathrm{sec}$. Long-life, multi-propellant resistojets are being developed for the Space Station, and resistojet technology advancements are being pursued to improve the $\mathrm{I}_{S p}$ by more than 20 percent for resistojets used in satellite applications. Direct current arcjets have the potential of $I_{S p}$ over $400 \mathrm{sec}$ with storable propellants and should provide over $1000 \mathrm{sec}$ with hydrogen. Advanced concepts are being investigated to provide high power density options and possible growth to primary propulsion applications. This paper summarizes NASA's broad-based experimental and analytical research and technology program and reviews recent significant advances.

\section{Nomenclature}

$A$ *

$\mathrm{Ae}_{\mathrm{e}}$

D

g

$I_{s p}$

$\dot{m}$

MPD

$\mathrm{Pa}_{\mathrm{a}}$

$P_{t}$

P

PPU

$\operatorname{Re}$

T

$T_{C}$

$T_{\mathrm{m}}$

$T_{\mathrm{V}}$

V

$\mu$

$n$

$\rho$ nozzle throat area, $\mathrm{m}^{2}$

nozzle exit area, $\mathrm{m}^{2}$

nozzle throat diameter, $m$ acceleration due to gravity, $\mathrm{m} / \mathrm{sec}^{2}$

specific impulse, $T / \dot{m g}$, sec

mass flow rate, $\mathrm{kg} / \mathrm{sec}$

magnetoplasmadynamic

ambient pressure, $\mathrm{Pa}$

total pressure at nozzle throat, $\mathrm{Pa}$

power, W

power processing unit

Reynolds number, $D V_{\rho} / \mu$

thrust, $\mathrm{N}$

corrected thrust, $\mathrm{N}$

measured thrust, $\mathrm{N}$

vacuum thrust, $\mathrm{N}$

velocity at nozzle throat, $\mathrm{m} / \mathrm{sec}$

viscosity at nozzle throat, $\mathrm{kg} / \mathrm{m} \mathrm{sec}$

efficiency

density at nozzle throat, $\mathrm{kg} / \mathrm{m}^{3}$
Introduction

The mass of propellant required for auxiliary propulsion limits the payload and/or lifetime of spacecraft, and propulsion system improvements such as increased specific impulse ( $I_{s p}$ ) can have strong mission benefits. Technology has advanced (Fig. 1) from low-performance cold-gas thrusters to monopropellant hydrazine thrusters ( $I_{S p}=220$ $\mathrm{sec}$ ) and more recently to electrically-augmented hydrazine resistojet thrusters ( $I_{S p}$ approaching $300 \mathrm{sec}$ ). The mission benefits from advanced auxiliary propulsion would help the U.S. industry maintain its lead in commercial applications, as well as provide enhanced capabilities for military and NASA programs.

NASA's auxiliary propulsion technology program includes the objective of developing electrothermal propulsion options for high specific impulse (arcjet) and high thrust-to-power ratio (resistojet), as well as developing long-life, multi-propellant resistojets for Space Station.

One of the most important characteristics of electric propulsion is illustrated in Fig. 2 , where thrust-to-power ratio (T/P) is plotted against Isp. The dashed line indicates the maximum electrical thrust to power ratio theoretically obtainable at each $\mathrm{I}_{\mathrm{sp}}$. (The ratio of thrust to power can be greater if the propellant enters the thruster with relatively high enthalpy.) Demonstrated results for various electric thruster and propellant combinations are shown by the various shaded regions. The electrothermal concepts, resistojets and arcjets, have higher T/P than electrostatic (ion) and magnetoplasmadynamic (MPD) approaches, but at lower Isp. Thus, although the reduction in propellant mass is not as great as for ion and MPD propulsion, the power requirement for a given thrust is less for the electrothermal concepts. Alternatively, electrothermal thrusters can provide a required total impulse in a shorter thrusting time.

Commonly used monopropellant hydrazine decomposition thrusters are limited in performance to $I_{S p}=220 \mathrm{sec}$. To provide higher performance, electrothermal devices are of considerable interest. The specific impulse attainable as a function of specific power input $(\mathrm{P} / \dot{\mathrm{m}})$ is shown in Fig. 3 for electrothermal thrusters with realistic system efficiencies for both catalytically decomposed hydrazine and cold inlet gas. The 220 sec "kick start" for hydrazine is a significant advantage, especially at specific power levels typical of resistojets.

In order to achieve the performance levels indicated for arcjets and high-performance resistojets ( $I_{S p} \gg 295 \mathrm{sec}$ ), a number of technologies must be addressed including several which are common to both concepts: heat transfer; low Reynolds number nozzles; low mass flow, high temperature efflux; power management; and propellant management. Significant advances in these areas are 
being produced by a broad-based experimental and analytical research and technology program. This effort consists of industrial, in-house, and academic activities. Resistojet and arcjet systems are the main subjects of these investigations, although some effort is also devoted to more advanced concepts.

The resistojet effort has two major objectives: long-life, multi-propellant resistojets for the Space Station and advanced, storable propellant resistojets for spacecraft. The technical challenges of these two efforts are significantly different. For the Space Station, performance is much less important than multi-propellant capability, very long life, user friendliness, and low risk. In contrast, the advanced resistojet effort is aimed at advancing the $I_{S p}$ to levels exceeding $350 \mathrm{sec}$ through improvements in thruster materials and fabrication techniques, heat exchanger performance, and nozzle performance.

Direct-current arcjets have the potential to exceed $400 \mathrm{sec} \mathrm{I}_{\mathrm{SP}}$ with storable propellants. Near-term application of arcjets at power levels on the order of $1 \mathrm{~kW}$ appear feasible since this power range is used for resistojet propulsion on some current satellites. Major issues being addressed in this program are performance, lifetime, stability, and integration with spacecraft systems. Considerable effort is also being devoted to the power processing unit and its integration with the thrusters.

Results are presented on these research and technology development efforts.

\section{Resistojets}

Resistojets are conceptually simple, as illustrated in Fig. 4. The propellant is heated by convection, conduction, and/or radiation from a resistively heated element and then expanded through a nozzle to produce thrust. Resistojets were flight tested as early as 1965 (Table 1 , updated from Ref. 1), and are now operational on about 25 spacecraft. 2 The operational state-ofthe-art for hydrazine resistojets is summarized in Table 2.

NASA is developing resistojet technology for the Space Station 2-8 and for high performance applications. 6 The objectives of this program are shown in Fig. 5. The Space Station development work emphasizes thruster life and multi-propellant capability, rather than high performance. The high performance resistojet program aims at $\mathrm{I}_{\mathrm{s}}$ exceeding $350 \mathrm{sec}$ with storable propellants by addressing materials compatibility, heat exchanger performance, and low Reynolds number nozzles as key technology areas. The program consists of efforts in industry, in-house, and in universities.

\section{Space Station}

The Lewis Research Center supports the Marshall Space Flight Center in component development of resistojet thrusters. Engineering model resistojet thrusters have been designed and fabricated by an industrial team (Fig. 6). The performance of these thrusters will be evaluated in-house.
Materials experiments have focussed primarily on the long-life, multi-propellant requirements of the Space Station. ${ }^{6-8}$ The compatibility of platinum grain-stabilized with yttria and with zirconia with several propellants was investigated. A series of $1000 \mathrm{hr}$ tests were conducted with carbon dioxide, methane, hydrogen, ammonia, steam, and nitrogen; $2000 \mathrm{hr}$ tests were done with carbon dioxide, hydrogen and ammonia.

Scanning electron microscopy (SEM), Auger electron spectroscopy, and depth profiling were performed. SEM photographs (e.g., Fig. 7(a)) showed negligible growth in all samples. In general the compatibility of these two materials with the candidate propellants was clearly established. However, with ammonia (Fig. 7(b)) both materials were roughened and pitted over the entire surface with some pitting at grain boundaries and with voids up to 50 percent into the material even though there was no mass loss.

Mass loss results are shown in Fig. 8, and the resulting lifetime estimates are shown in Fig. 9 . The projected lifetimes exceed Space Station requirements. However, further research is clearly needed with ammonia and hydrazine, which has ammonia as one of its decomposition products. Materials already demonstrated with hydrazine should also be compatible with ammonia.

As an element of the Space Station resistojet program, dc and ac output controllers were designed, fabricated, and tested (Fig. 10). The controller provides precise resistance control to maintain heater temperatures. This enables the controller to accommodate blow-down systems and bus voltage changes, and it eliminates the requirement of delicate heater elements by matching the power bus to the heater. The control of resistance and temperature allows trade-offs to be made between heater life and performance. The electronics developed provide soft turn on characteristics, which increases heater life and reduces spacecraft bus current transients, and can isolate spacecraft ground from the heater element, if required.

The exhaust plumes of auxiliary propulsion thrusters are of concern both due to effects of impingement, such as thrust loss and heating, and contamination. The contamination issue is of particular concern for the Space Station. To address these issues an in-house capability (Fig. 11) is being developed. An experimental set-up has been designed and fabricated; mass flux data are being obtained with commercially available quartz crystal microbalances, and total pressure probes (variable angle) are being used to obtain velocity streamlines. Preliminary mass-flux measurements are underway with a low-power (0 to $150 \mathrm{~W}$ ) inconel resistojet with carbon dioxide propellant. Considerable effort is being devoted to reconciling plume models with experiment to allow prediction of column density and deposition for the Space Station. The capabilities developed for plume diagnostics will also be needed for the advanced resistojet and arcjet programs.

\section{Advanced Resistojets}

Two types of heat exchangers are used for state-of-the-art resistojet systems, as shown in Fig. 12. The High Performance Electrothermal Hydrazine Thruster (HiPEHT) approach shown in 
Fig. 12(a) employs vortex propellant flow directly over the heating element, thus allowing the propellant temperature to approach the heating element temperature. In the Augmented Catalytic Thruster (ACT) (Fig. 12(b)), the heating element does not contact the propellant directly; instead it radiates to a heat exchanger through which the propellant flows.

Another design approach is the coiled-tube heat exchanger (Fig. 13). A rhenium coiled-tube design offers the potential of high performance, but long term durability is a concern because of sag and coil-to-coil movement.

Improved nozzle performance will be a key to approaching the target performance levels at temperatures low enough to provide useful thruster life. The Reynolds numbers (based on throat diameter) are very low, typically less than $10^{3}$. Therefore, the boundary layer is quite thick and the flow field is considerably different from the relatively well understood potential flow case. Calculated low Reynolds number results ${ }^{9}$ are shown in Fig. 14, where Mach number contours and streamwise velocity vectors are shown. The thick boundary layer is evident, and the peak Mach number occurs shortly downstream of the throat. Because of the strong viscous effects, much of the flow field is subsonic, and ambient conditions can significantly affect nozzle performance.

Because of these unique characteristics, the determination of facility effects is especially important. Therefore, tests have been conducted to investigate the effect of vacuum facility pressure on the performance of small thruster nozzles. 10 Thrust measurements of two converging diverging nozzles having area ratios of 140 and an orifice were obtained over a wide range of ambient pressure and throat Reynolds number (Re) using unheated hydrogen ( $\mathrm{Fig} .15)$. In the 2200 to $12000 \mathrm{Re}$ range there was no effect of ambient pressure for nozzle pressure ratios, $\mathrm{P}_{t} / \mathrm{P}_{\mathrm{a}}>10^{4}$, and the effects can readily be corrected down to $\mathrm{Pt}_{t} / \mathrm{P}_{\mathrm{a}} \approx 10^{3}$. This appears to set an upper limit for ambient pressure, and this limitation may be even more severe at lower Re. Experimental and computational fluid mechanics approaches are being applied to this problem.

\section{Arcjets}

An arcjet is an electrothermal thruster wherein the propellant is heated by an electric arc, as illustrated in Fig. 16. The hightemperature arc is sustained between the tip of the thermionic cathode and the anode. Ideally, the arc is forced through the constrictor to a diffuse attachment on the anode. In the conventional design (Fig. $16(\mathrm{a})$ ), the desired attachment region is in the supersonic portion of the nozzle, and so the arc is kept away from contact with the internal surfaces of the engine. This alleviates the performance limitations due to the material properties of the thruster. A promising alternative to the conventional arcjet design incorporates a mixing chamber between the anode attachment region and the nozzle, as shown in Fig. 16(b). Both the conventional and mixing chamber approaches are being investigated.

The power available to auxiliary propulsion on communications satellites is currently limited to 0.5 to $1.5 \mathrm{~kW}$. Arcjet thrusters operated with storable propellants in the above mentioned power range should provide specific impulse of 400 to $500 \mathrm{sec}$ and so offer large benefits to the user community. The simplicity of the arcjet system and its elements of commonality with state-of-the-art resistojet systems offer a relatively low risk transition to this level of performance.

The possible application of higher power arcjets to orbit-transfer primary propulsion has attracted the interest of the U.S. Air Force.11 Because of the joint interest in this technology area, a Memorandum of Agreement has been established between Lewis and the Air Force Rocket Propulsion Laboratory. Mutual benefits should result from this cooperative effort.

\section{Energy Distribution}

Arcjets do not always operate in the ideal mode described earlier in this section. Figure 17 illustrates two modes thought to represent the extremes of arcjet operation. The "high" mode is as described earlier with the arc attachment in the nozzle in a diffuse manner; operation is stable and nondestructive. In the "low" mode, the attachment is at the upstream end of the constrictor in a spot mode; this mode is characterized by rapid anode erosion and unstable performance. From the bar chart it can be seen that the high mode is more efficient, with a higher fraction of the power being deposited in the propellant. 12 Consequently, higher $\mathrm{I}_{\mathrm{Sp}} \mathrm{c}$ an be obtained in the high mode. Tests were conducted with nitrogen propellant over a wide range of geometries and power levels from 0.3 to $1.7 \mathrm{~kW}$. Typical results are shown in Fig. 18, where power is plotted against arc current. Total power input is shown by the upper curve (diamond symbols), the squares indicate the power lost to the electrodes, and the circles indicate the power loss to the cathode. Thus, the difference between the diamonds and squares represents the energy deposited in the propellant. These energy balance measurements indicated that less than 5 percent of the total arc power was lost to the cathode assembly, while 20 to 25 percent was typically lost at the anode in the high mode. In the low mode, anode losses were greater.12

Stability

It is critically important to establish a stable, low power arc in the high mode in order to achieve efficient operation in the range normally budgeted for propulsion on communications satellites. However, previous arcjet investigations 14 in this power range with storable propellants were relatively unsuccessful, although limited positive results were obtained with hydrogen. One way to stabilize the operation is to impart a vortex flow pattern to the propellant entering the arc chamber.12,14,15 This forces a region of low pressure on the centerline, thereby creating a path of least resistance (highest electrical conductivity) for the arc in the desired location. This may provide an advantage in that the high axial velocity regions are remote from the cathode tip, so that redeposition of evaporated or sputtered cathode material is possible. It has an additional benefit, since it centrifuges the cooler, dense gas to the walls. 12 
To study stability criteria and establish baselines for further research, a modular watercooled thruster simulator was designed and built, with axial and tangential feed lines machined into the arc chamber insulator to allow flow pattern flexibility. A series of thoriated tungsten anode inserts was also machined to permit variation of the engine constrictor dimensions, and experiments were run using nitrogen propellant. Early in these experiments a relatively large constrictor diameter $(1.27 \mathrm{~mm})$ was used. A variety of flow patterns gave unsatisfactory results, until it was found that tangential injection of the propellant produced stable operation in the high mode. Once this condition was established, axial flow could be added with very little change in performance. In some cases, the addition of axial flow slightly extended the power limit for stable, high mode operation. The range of stable, high mode operation is shown in Fig. 19, wheire input power is plotted against constrictor diameter. Results of demonstrated stable operation obtained with hydrogen arcjets in the 1960's are shown for comparison. It can be seen that power levels on the order of those currently used for propulsion on communications satellites can be obtained with the $0.64-\mathrm{mm}$ diameter constrictor ysing controlled tangential and axial injection. 12

\section{Power Processor Integration}

Representative steady state voltage-current characteristics of an arcjet are shown in Fig. 20.16 The decreasing voltage with increasing current, or negative resistance characteristic,

nstead of a positive resistance characteristic of most devices, including resistojets, presents unique stability problems. In order to stabilize the system, a larger positive resistance must be added in series with the arc. The simplest approach is to add a ballast resistor, and the characteristic of a ballasted supply is superimposed on the arc characteristics in Fig. 20. This would not be a practical solution, however, since significant energy would be lost through the ballast resistor, and that would also create a significant thermal load. A more efficient approach is a high frequency pulse width modulator power converter configured in a closed loop to give fast response output current control.16 The steepness of the output curve of this pulse width modulated supply, as shown in Fig. 20, implies good current regulation and should be helpful in minimizing arc current varjations during rapid changes in arc resistance. 16

Changes in arc voltage may be associated with movements of the arc/anode attachment location, such as a change from high to low mode (Fig. 16) or an intermediate condition. Mode changes can result from intentional changes or occur spontaneously. Figure 21 illustrates the importance of the power supply in controlling the arc mode. Figure 21(a) illustrates the response of the ballasted supply to a spontaneous voltage change from 76 to $52 \mathrm{~V}$ at $10 \mathrm{~A}$ current. Attempts to restore the high mode by stopping and restarting were unsuccessful. A quick change to the modulated supply and a restart led to restoration of the high mode (Fig. 21(b)) at essentially the same arc voltage as with the ballasted supply. Although over extended operation there were excursions to low voltage, each time the thruster/PPU returned quickly to the high mode. 13 Thus, the thruster/PPU interaction is critical to arcjet stability.

Another unique requirement of the arcjet is arc starting. Several methods of starting have been employed, such as touching the electrodes momentarily, reducing chamber pressure until Paschen breakdown is obtained, or placing a high voltage across the electrodes until the arc starts. Using the latter approach, the starting function can be incorporated in the PPU. An inductor in series with the load provides a high voltage ignition pulse in addition to providing the instantaneous current control during sustained operation. This latter method appears to be most promising, since the current is kept low throughout the starting transient, thereby minimizing electrode damage. 16

The energy efficiency of the power processing unit is also an important consideration. This pulse width modulated supply achieved 90 percent efficiency, even though the design was not optimized. 16

\section{Lifetime}

Limitation of thruster life, primarily due to electrode erosion, has long been recognized as a major technical issue. 17 Stable operation with vortex flow in conjunction with careful starting techniques were found effective in minimizing electrode damage. In early experiments on the thruster simulator the cathodes showed visible erosion away from the tip, near the boron nitride insulator (Fig. 22(a)). This type of damage was eliminated by starting with a full vortex flow field (Fig. 22(b)). Since the exposed cylindrical surfaces of the cathode pieces were smooth, it was concluded that the vortex forced emission from the cathode tip. 12

The condition of the anode was found to be dependent on stability, as well as starting, as shown in Fig. 23. Fig $23(\mathrm{a})$ is a photograph of the nozzle side of an anode which was started gently and operated only in the high mode; there is no evidence of damage. Fig. 23(b) shows a similar anode/nozzle which was operated for a significant time in the low mode with unstable conditions; there is considerable damage. 12

Because of the performance and system commonality benefits attainable by using hydrazine propellant, it is necessary to assess the influence of propellant grade hydrazine on life. This hydrazine contains water and carbon dioxide as well as other impurities which could accelerate erosion. Therefore, a facility has been installed at Lewis to address these potential problems, and preliminary tests are under way. The industrial program is also addressing this important issue. ${ }^{18}$

\section{Performance}

In order to establish a baseline for low power arcjet performance, thruster level testing was initiated using an existing thruster originally designed for a short-duration flight using hydrogen propellant. 13 Rapid erosion of the constrictor occurred in the initial testing, increasing the diameter from about 0.23 to $0.76 \mathrm{~mm}$ and reducing its length to a sharp edge, but throughout further testing in excess of $40 \mathrm{hr}$ little or no additional 
erosion was seen. Because of the early erosion the nozzle area ratio was reduced from 30 to about 2.8, leading to poor nozzle performance. With the subsequent addition of a nozzle extension, over 30 percent efficiency was obtained at $I_{\text {sp }}=420 \mathrm{sec}$. Sustained tests of up to $2 \mathrm{hr}$ duration exhibited no apparent performance degradation with time.13

To build upon the foundation established by these early results, 13 the thruster has, been modified for further testing (Fig. 24).15 The previously mentioned nozzle extension is shown in Fig. 24(b). For the more recent tests, the original insert was replaced by a 2 percent thoriated tungsten piece machined to be similar to the original on the chamber side, but with a $0.64 \mathrm{~mm}$ diameter, $1.14 \mathrm{~mm}$ long constrictor. The nozzle half angle was 19 degrees, and the area ratio was 56 . A $30^{\circ}$ nozzle extension was also tested, providing an area ratio of 3300 . The results of these experiments are shown for simulated storable propellants (nitrogen-hydrogen mixtures) in Fig. 25. Efficiency, Isp, and arc power are plotted against current. Stable operation was obtained over a 660 to $1170 \mathrm{~W}$ range, with efficiency decreasing slightly, $0.35 \geq n \geq 0.27$, with increasing power. Isp as high as $44 \overline{0}$ was obtained with simulated hydrazine and 500 with simulated ammonia. The performance of both area ratio nozzles was about the same, but this does not preclude the possibjlity of an optimum at some intermediate area ratio. 15

\section{Advanced Concepts}

Two advanced electrothermal concepts are being investigated, although both concepts have unique characteristics which may lead to applications outside the field of auxiliary propulsion, for example primary propulsion and materials processing.

\section{Pulsed Electrothermal Thruster}

The pulsed electrothermal (PET) thruster concept is intended to avoid material temperature limits by operating at megawatt power levels over microsecond bursts, with milliseconds between pulses.19 An additional benefit obtained from the high pressure levels achieved with the pulse is that the supersonic nozzle flow is at near equilibrium, so that the ionization energy of the propellant is recovered. Promising results have been obtained for the single-shot experiments using the ablative-wall thruster; efficiencies ranged from 0.56 to 0.37 at specific impulses from 1000 to $1700 \mathrm{sec}$. A PET thruster system has been proposed using water as a propellant to ease the feed problem and provide 50 percent efficiency at $1000 \mathrm{sec}$ specific impulse. Experimental verification of this advanced thruster in a multi-shot mode is being conducted by GT-devices.

\section{Microwave Electrothermal Arcjet}

Another advanced electrothermal propulsion concept of interest is the microwave electrothermal arcjet. This concept is similar in principle to dc arcjets except an ac microwaye discharge is utilized to heat propellant.20-26 The advantages of this concept are similar to those of the dc arcjet in that the propellant cain be heated to temperatures above thruster material limits. Exploratory experiments 20,21 conducted at power 1evels up to $600 \mathrm{~W}$ have demonstrated that it is possible to couple microwave power to nitrogen, oxygen, and helium arcs with efficiencies in excess of 99 percent. Cylindrical discharges were formed which contracted away from the walls as expected at pressures above 100 torr. This phenomenon is potentially of great interest as it may allow the generation of extremely energetic and high density plasmas without direct contact with chamber walls. This ability to establish a very intense, efficient discharge away from 'walls could imply very significant benefits in both efficiency and lifetime for the microwave arcjet approach and lead to very high power applications. Thrust measurements on the coaxial and cylindrical cavity thrusters have been obtained. 23 Measured energy efficiencies ranging from 10 to 60 percent were obtained using nitrogen gas at $200 \mathrm{~W}$ to $2 \mathrm{~kW}$ power levels and specific impulses up to $250 \mathrm{sec}$.

\section{Concluding Remarks}

Significant advances in electrothermal propulsion are being produced by a broad-based experimental and analytical research and technology program. This effort consists of industrial, in-house, and academic activities.

In order to demonstrate Space Station readiness of the technology for the long-life, multipropellant resistojet, laboratory model thrusters fabricated from grain-stabilized platinum were subjected to endurance testing with carbon dioxide propellant; over $12001-\mathrm{hr}$ cycles have been completed. The performance of these thrusters has been characterized with hydrogen, helium, methane, air, nitrogen, and carbon dioxide, and compatibility with these propellants has been established.

Resistojets using hydrazine decomposition products are in operational use on spacecraft at $\sim 295 \mathrm{sec}$ specific impulse. Specific impulses exceeding $350 \mathrm{sec}$ may be achievable through advances in thruster materials and processing techniques, heat exchanger performance, and nozzle performance.

Direct-current arcjets have the potential to exceed $400 \mathrm{sec}$ specific impulse with storable propellants. Prospects for near-term application of arcjets at power levels on the order of $1 \mathrm{~kW}$ appear feasible since this power range is used for propulsion on some current satellites. Major issues being addressed are stability, lifetime and performance. Considerable effort is also being devoted to the power processing unit and its integration with the thrusters. An early thruster design has already demonstrated thrust efficiency of 31 percent at $420 \mathrm{sec}$ specific impulse using simulated ammonia (gas mixture). Reasonably stable operation was obtained with a pulse width modulated power processing unit, and over $40 \mathrm{hr}$ of testing were completed. More recent results with an improved thruster show that specific impulses as high as $440 \mathrm{sec}$ with simulated hydrazine and 500 sec with simulated ammonia can be obtained with a $1-\mathrm{kW}$ class thruster.

\section{References}

1. Mirtich, M.J., "Resistojet Propulsion for Large Spacecraft Systems," AIAA Paper 82-1948, Nov. 1982 . 
2. Morren, W.E., Whalen, M.V., and Sovey, J.S., "Performance and Endurance Tests of a Multipropellant Resistojet for Space Station Auxiliary Propulsion," AIAA Paper 86-1435, June 1986

3. Penko, P.L., Staiger, P.J., and Bur, M.J., "An Analysis of Low-Thrust, Resistojet Reboost for the Space Station," AIAA Paper 85-2042, Sept. 1985.

4. Jones, R.E., "Space Station Propulsion: The Advanced Development Program at NASA-Lewis," AIAA Paper 85-1154, July 1985.

5. Pugmire, T.K., Cann, G.L., Hechert, B. and Sovey, J.S., "A 10,000-Hour Life Multipropel1 ant Engine for Space Station Application," AIAA Paper 86-1403, June 1986.

6. Whalen, M.V., Grisnik, S.P., and Sovey, J.S., "Compatibility Experiments of Facilities, Materials, and Propellants for Electrothermal Thrusters," NASA TM-86956, 1985.

7. Whalen, M.V., and Grisnik, S.P., "Compatibility of Grain Stabilized Platinum with Candidate Propellants for Resistojets," AIAA Paper 85-2014, Sept. 1985.

8. Whalen, M.V., "Grain Stabilized Platinum Compatibility for Space Station Resistojets, " NASA TM- , to be published, 1986.

9. Sovey, J.S., Penko, P.S., Grisnik, S.P., and Whalen, M.V., "Vacuum Chamber Pressure Effects on Thrust Measurements of Low Reynolds Number Nozzles," NASA TM-86955, 1985.

10. Anderson, B., "Preliminary Low Reynolds Number Nozzle Computations." Unpublished.

11. Vondra, R.J., "U.S. Air Force Development of Electric Propulsion," AIAA Paper 85-1998, Sept. 1985.

12. Curran, F.M., "An Experimental Study of Energy Loss Mechanisms and Efficiency Considerations in the Low Power dc Arcjet," AIAA Paper 85-2017, Sept. 1985.

13. Nakanishi, S., "Performance Evaluation of a 1 KW Arcjet Thruster," AIAA Paper 85-2033, Oct. 1985.

14. Wallner, L.E., and Czika, J., Jr., "Arc-Jet Thrustor for Space Propulsion," NASA TN D-2868, 1965.

15. Curran, F.M., and Nakanishi, S., "Low Power dc Arcjet Operation with Hydrogen/Nitrogen Propellant Mixtures," AIAA Paper 86-1505, June 1986.
16. Gruber, R.P., "Power Electronics for a $1 \mathrm{~kW}$ Arcjet Thruster, " AIAA Paper 86-1507, June 1986.

17. Hardy, T.L., "Electrode Erosion in Arc Discharges at Atmospheric Pressure," AIAA Paper 85-2018, Sept. 1985.

18. Knowles, S.C., Curran, F.M., and Smith, W.W., "Transient and Steady State Electrode Erosion Characteristics of an Arcjet Thruster," AIAA Paper 86-1506, June 1986.

19. Burton, R.L., Goldstein, S.A., Hilko, B.K., Tidman, D.A., and Winsor, N.K., "Investigation of a Pulsed Electrothermal Thruster System," GT-Devices, Alexandria, VA, GTD-84-4, Oct. 1984. (NASA CR-174768)

20. Whitehair, S., and Asmussen, J., "The Generation and Maintenance of Stable High Pressure Microwave Arcs," Proceedings of the Fifth Topical Conference on Radio Frequency PTasma Heating, Madison, WI, Feb. 21-23, 1983, pp. 296-299.

21. Whitehair, S., and Asmussen, J., "Measurements of the Electromagnetic Field Patterns Surrounding Atmospheric Microwave Discharges," 1983 IEEE International Conference of Plasma Science, IEEE, 1983, p. 145.

22. Whitehair, S., Asmussen, J., and Nakanishi, S., "Demonstration of a New Electrothermal Thruster Concept, "Applied Physics Letters, Vol. 44, No. 10, May 15, 1984, pp. 1014-1016.

23. Whitehair, S., Asmussen, J., and Nakanishi, S., "Experiments with a Microwave Electrothermal Thruster Concept," International Electric Propulsion Conference, 17th, Japan Society for Aeronautical and Space Science, Tokyo, 1984, pp. 529-540.

24. Whitehair, S., Asmussen, J., Jr., and Nakanishi, S., "Recent Experiments with Microwave Electrothermal Thrusters." AIAA Paper 85-2051, 0ct. 1985.

25. Frasch, L., and Asmussen, J., Jr., "Electrothermal Propulsion of Spacecraft with Time-Varying Electromagnetic Energy," AIAA Paper 85-2050, 0ct. 1985.

26. Chapman, R., Finzel, M., and Hawley, M. "Measurements of Energy Distribution and Wall Temperature in Flowing Microwave Plasma Systems," AIAA Paper 85-2052, Oct. 1985. 
TABLE 1. - RESISTOJET FLIGHT HISTORY

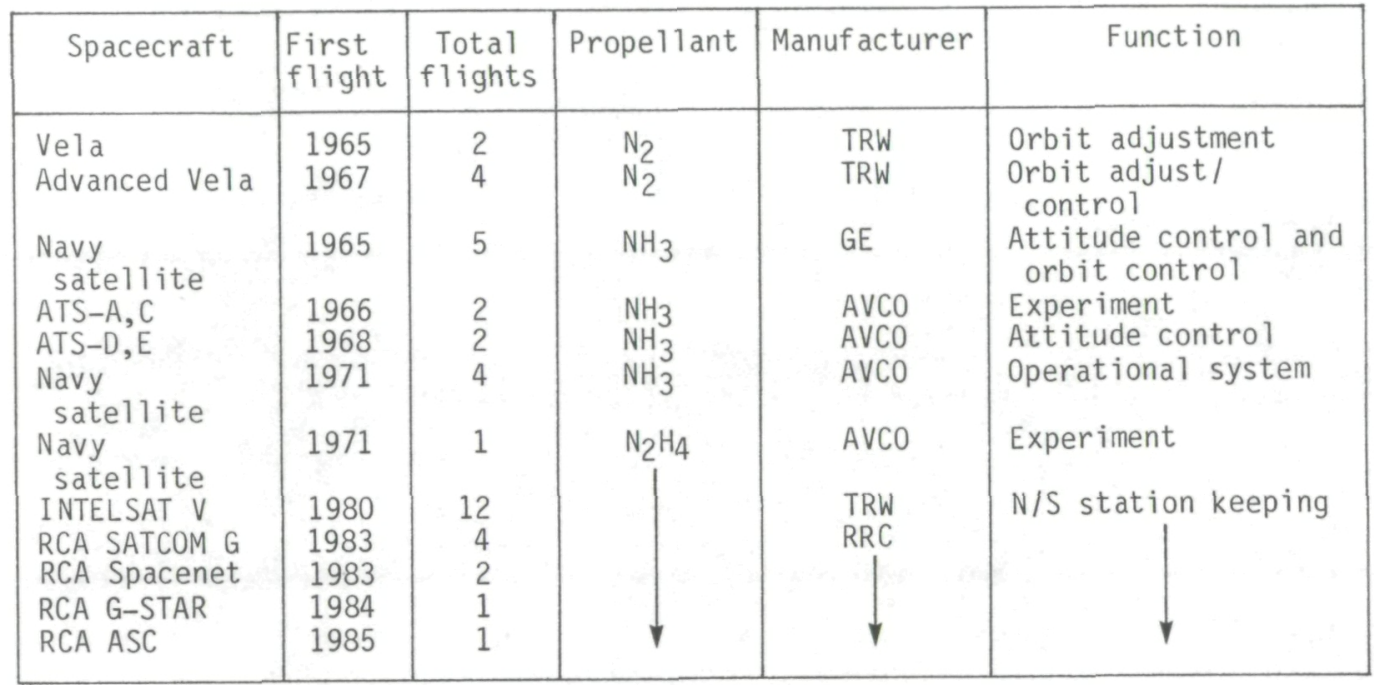

TABLE 2. - RESISTOJET STATE OF THE ART

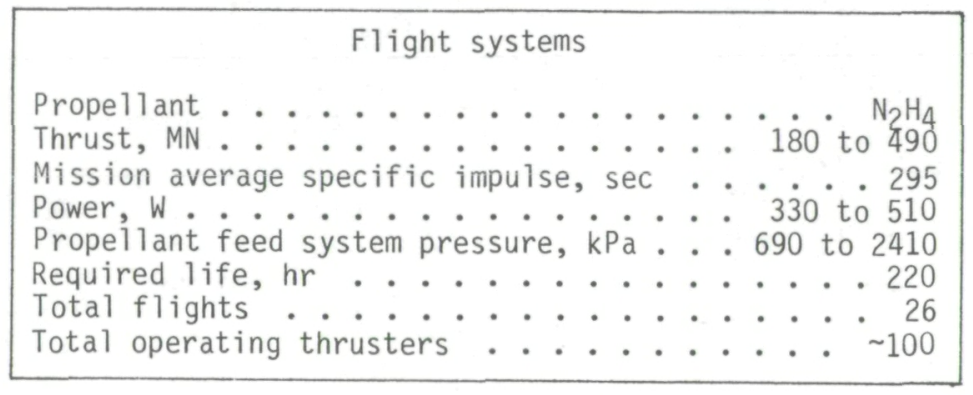




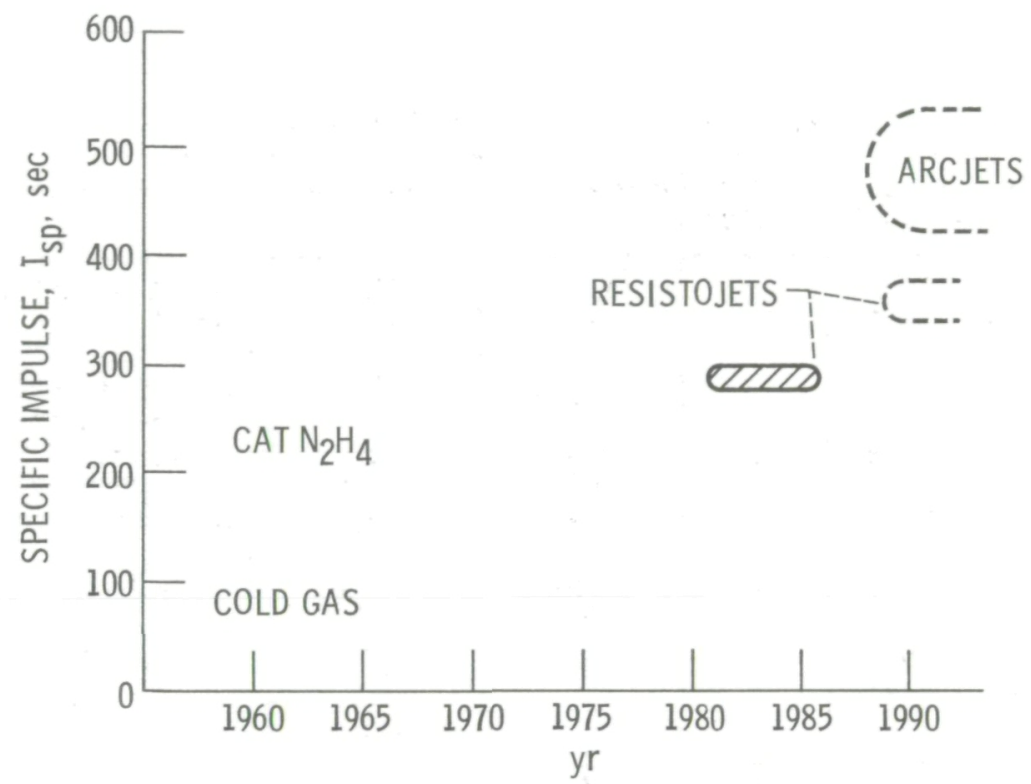

Figure 1. - Evolution of hydrazine electrothermal auxiliary propulsion.

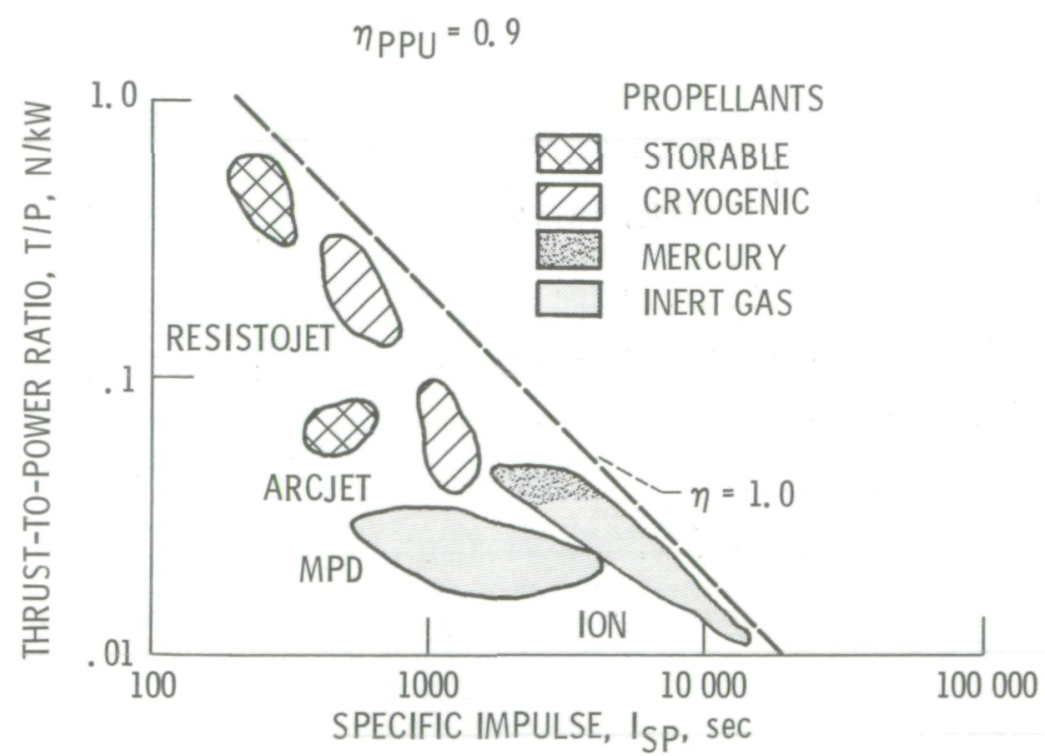

Figure 2. - Thrust-to-power ratio versus specific impulse. 


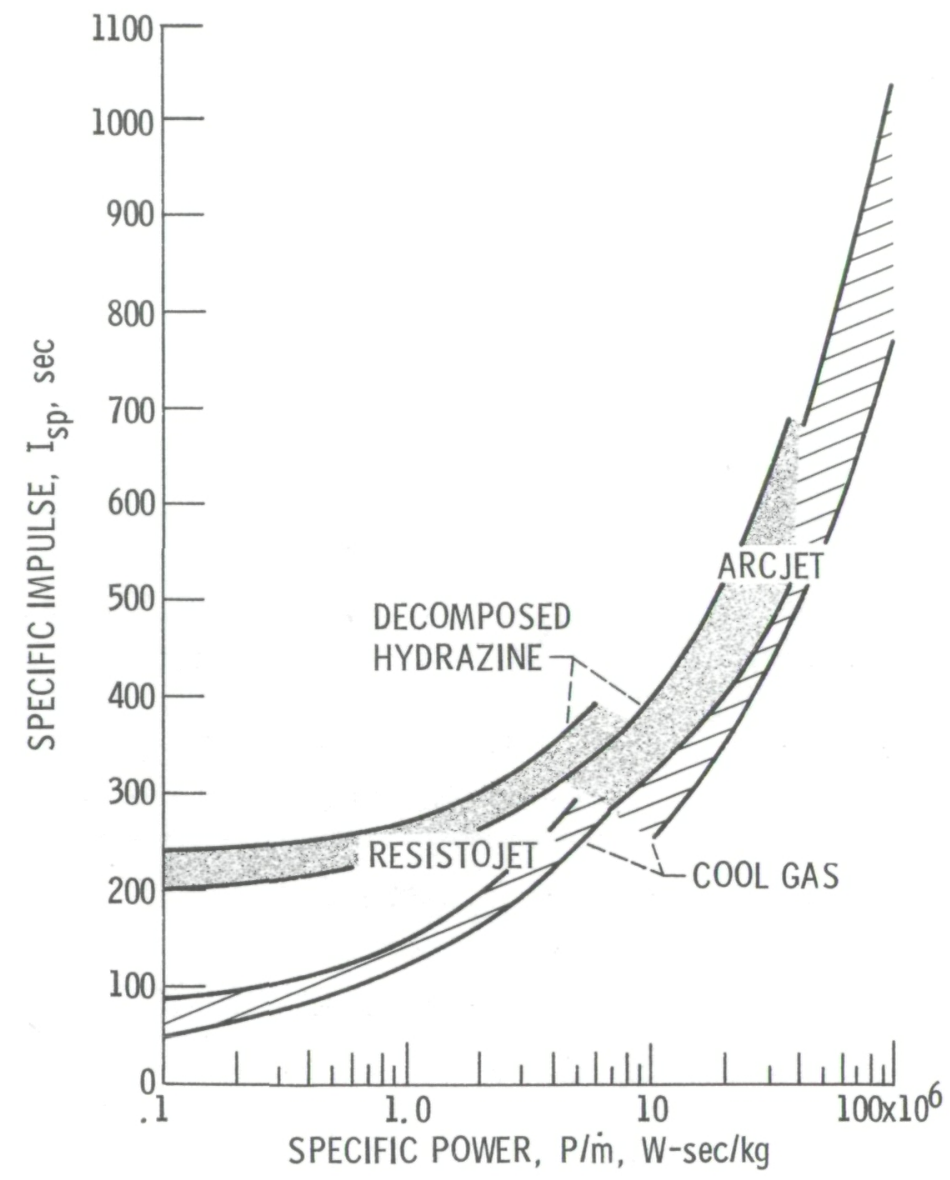

Figure 3. - Specific impulse as function of specific power.

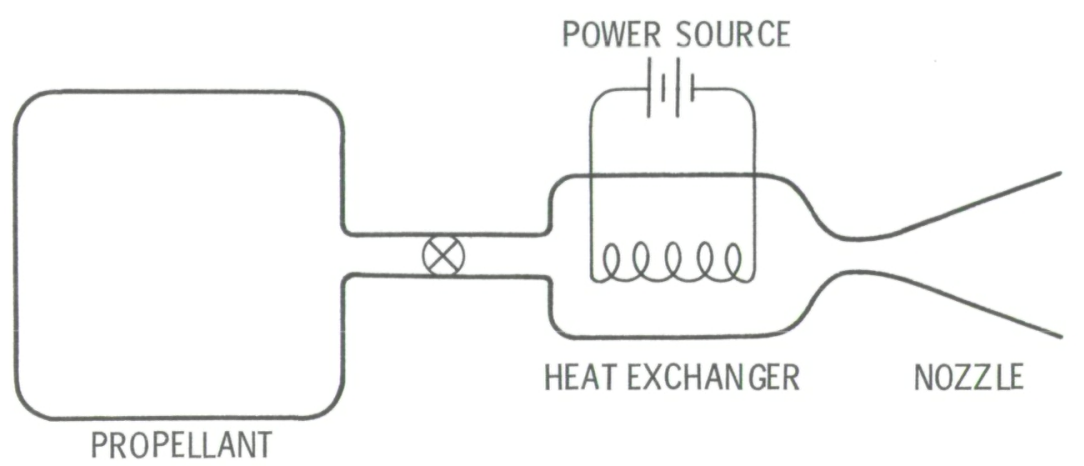

Figure 4. - Resistojet schematic. 
APPLICATION

SPACE STATION

ADVANCED SPACECRAFT
PROGRAM GOALS

- MULTI-PROPELLANT CAPABILITY

- 10000 hour LIFE

- $\mathrm{I}_{\mathrm{sp}}>350$ seconds

- 500 hour LIFE

- STORABLE PROPELLANTS

Figure 5. - Objectives of restojet program. 

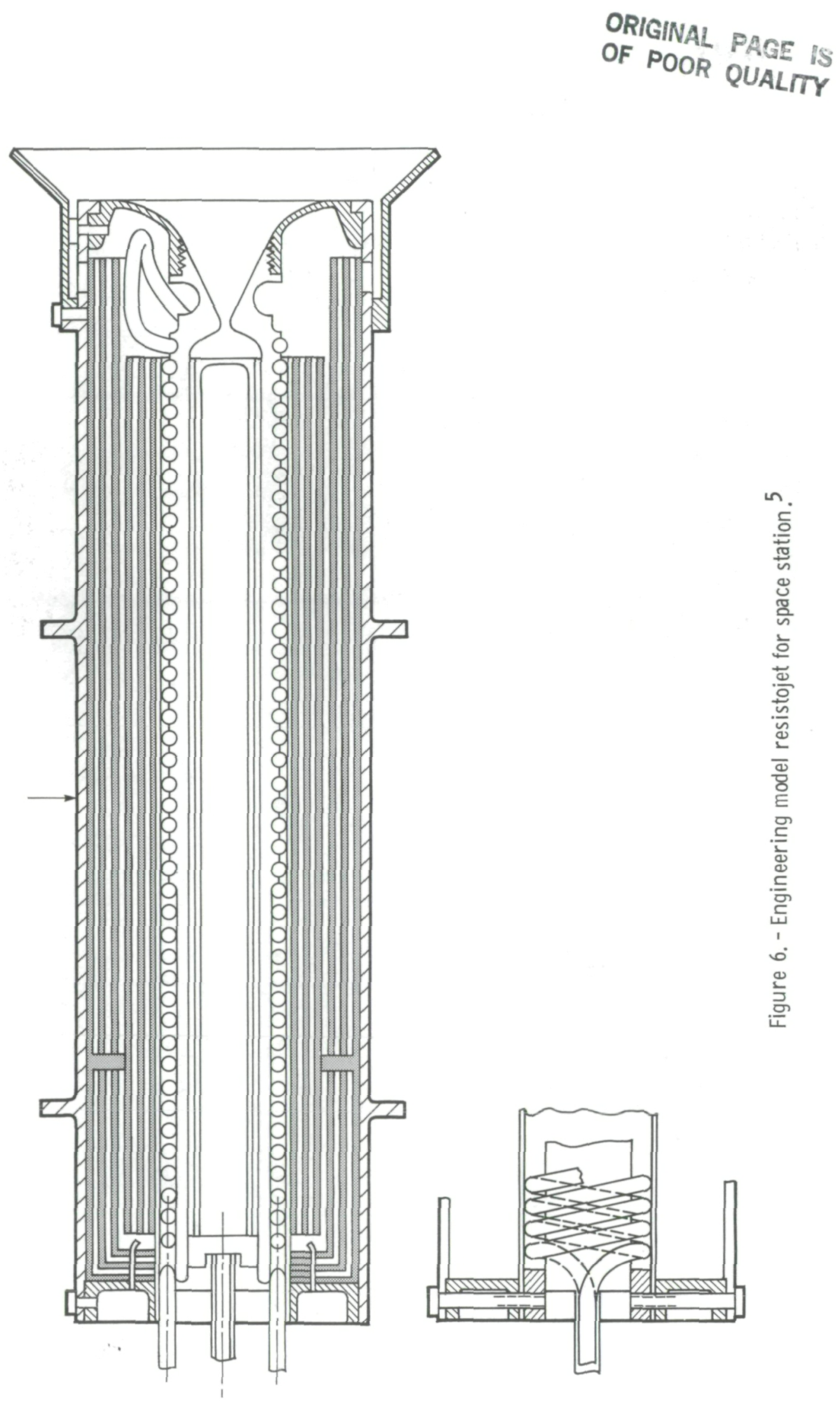
- GRAIN GROWTH NOT A PROBLEM
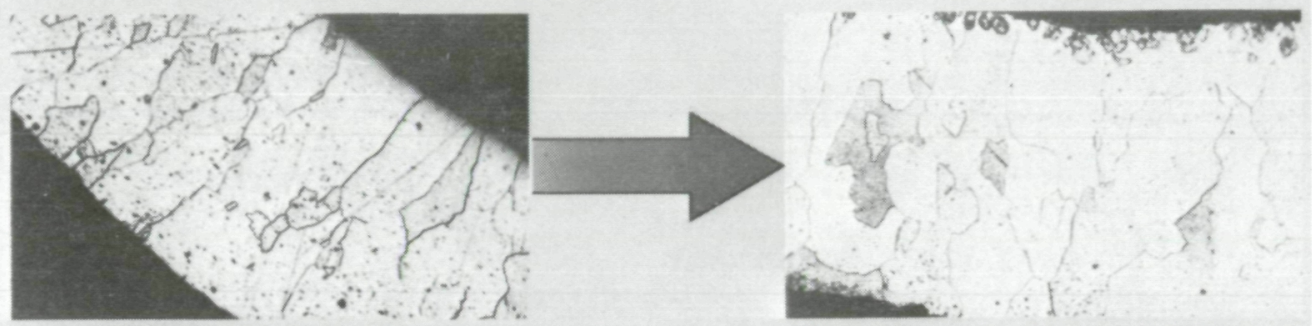

ANNEALED Pt/ $\mathrm{Y}_{2} \mathrm{O}_{3}$

(AVE. GRAIN SIZE $\cong 37 \mu \mathrm{m}$ )

$\mathrm{Pt} / \mathrm{Y}_{2} \mathrm{O}_{3} \Rightarrow \mathrm{H}_{2}, 1000 \mathrm{hr}$ AT $1400^{\circ} \mathrm{C}$ (AVE. GRAIN SIZE $\cong 38 \mu \mathrm{m}$ )

(a) With hydrogen.

- QUESTION WITH $\mathrm{NH}_{3}$ CONTAINING COMPOUNDS

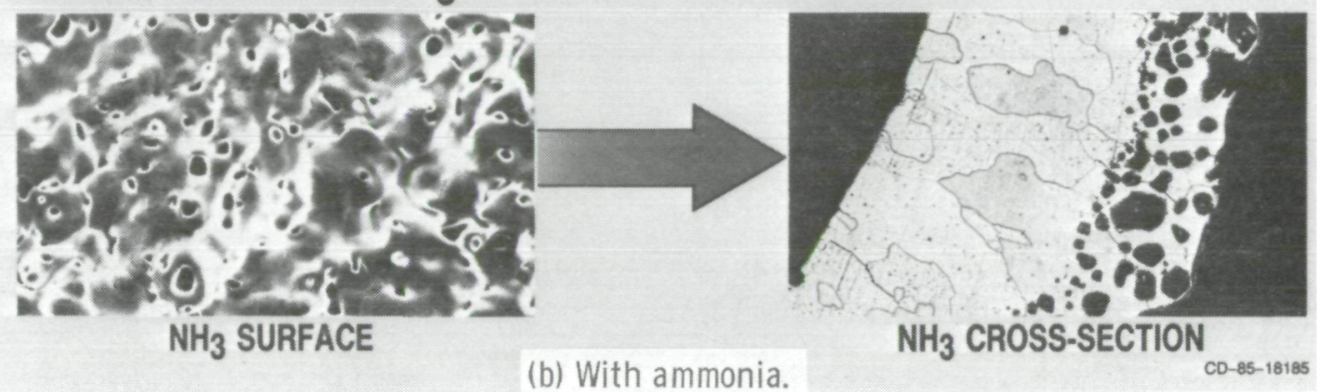

Figure 7. - Compatibility results ${ }^{8}$.

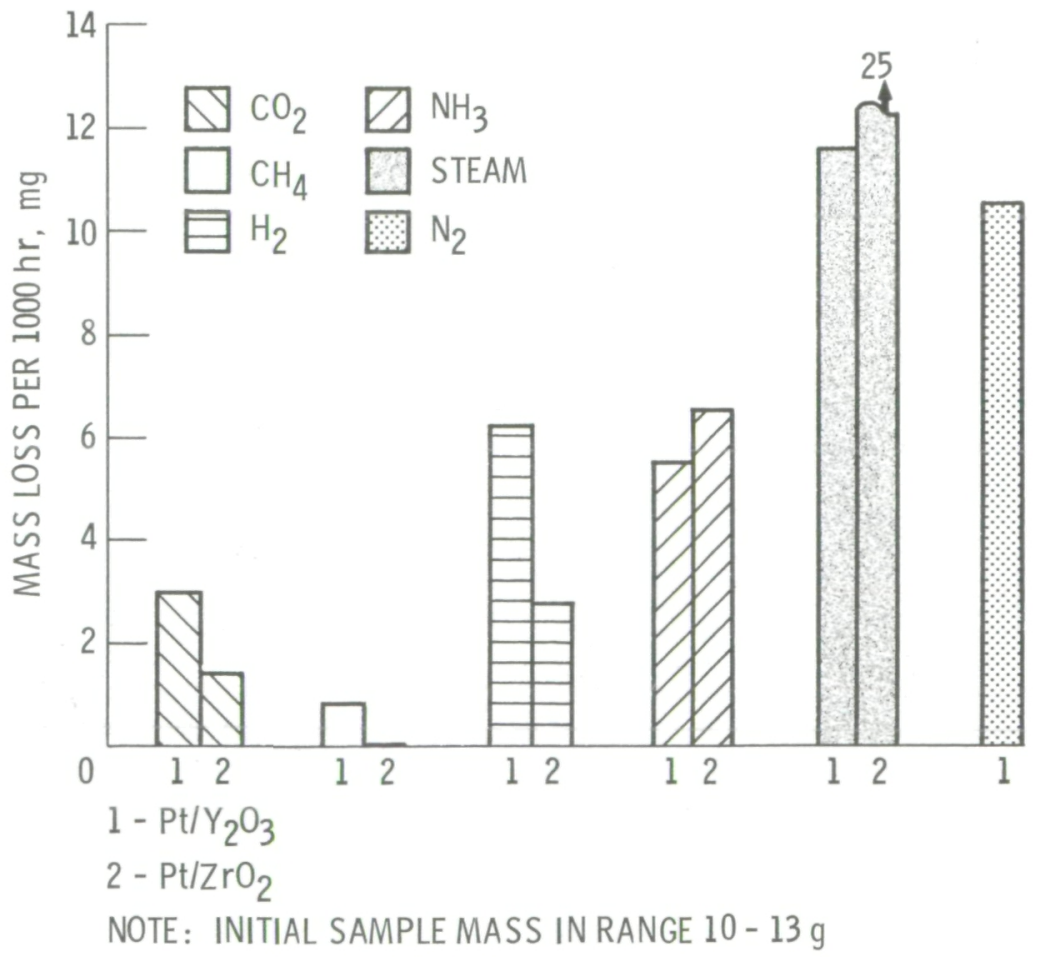

Figure 8. - Mass loss results from compatibility experiments. ${ }^{8}$ 


\begin{tabular}{|l|c|c|}
\hline & $\begin{array}{c}\mathrm{Pt} / \mathrm{Y}_{2} \mathrm{O}_{3}, \\
\mathrm{KHr}\end{array}$ & $\begin{array}{c}\mathrm{Pt} / \mathrm{ZrO}_{2}, \\
\mathrm{KHr}\end{array}$ \\
\hline $\mathrm{CO}_{2}$ & 300 & 800 \\
$\mathrm{CH}_{4}$ & 1500 & 1500 \\
$\mathrm{H}_{2}$ & 200 & 400 \\
$\mathrm{~N}_{2}$ & 106 & ---- \\
$\mathrm{NH}_{3}$ & 200 & 200 \\
STEAM & 110 & 45 \\
\hline
\end{tabular}

- LIFETIMES EXTRAPOLATED LINEARLY FROM 1000 hOUR TEST RESULTS

- $10 \%$ MASS FAILURE CRITERION

- LIFETIMES EXCEED LIFE REQUIREMENTS

Figure 9. - Estimated thruster lifetime. ${ }^{8}$

- PROVIDES PRECISE RESISTANCE CONTROL

- CAN ACCOMMODATE BLOW-DOWN SYSTEMS AND BUS VOLTAGE CHANGES

- Eliminates REQUIREMENT OF DELICATE hEATER ELEMENTS - MATCHES POWER BUS TO HEATER

- ALLOWS HEATER LIFE/THRUSTER PERFORMANCE TRADE

- PROVIDES SOFT TURN ON CHARACTERISTICS

- INCREASES HEATER LIFE

- REDUCES SPACECRAFT BUS CURRENT TRANSIENT

- CAN ISOLATE SPACECRAFT GROUND FROM HEATER ELEMENT IF REQUIRED

Figure 10. - Resistojet control and power electronics. 


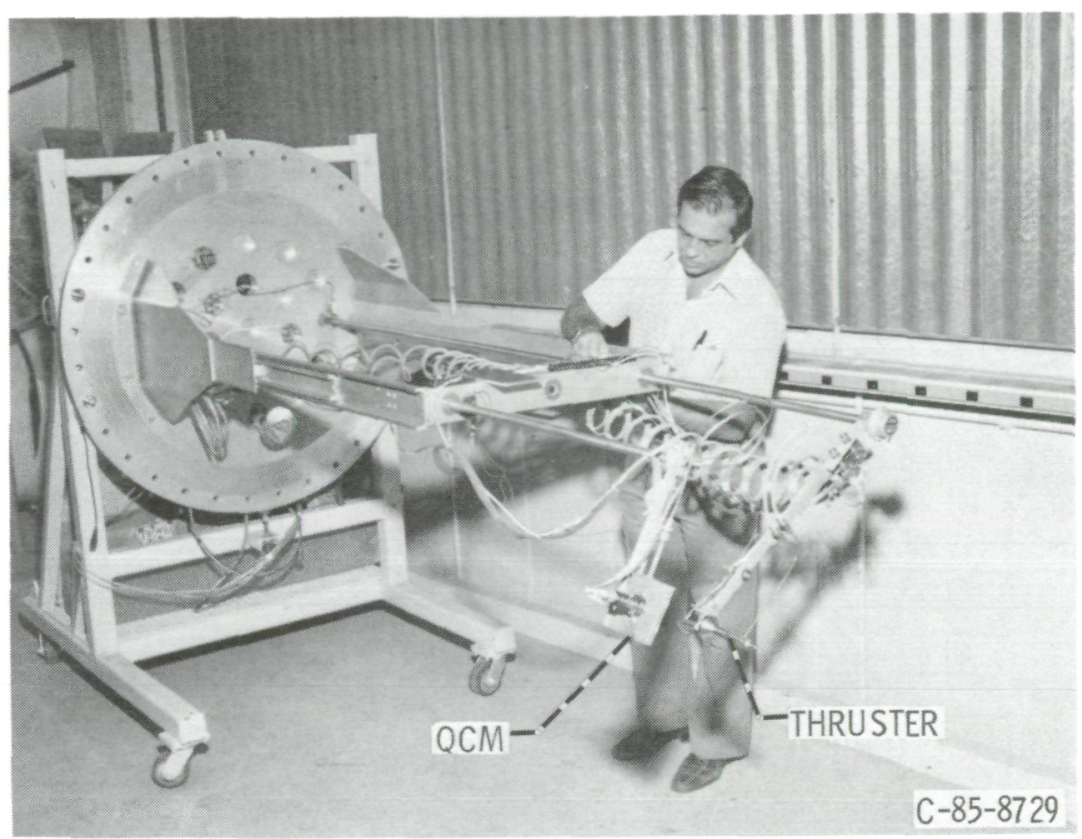

Figure 11. - Plume diagnostics apparatus.

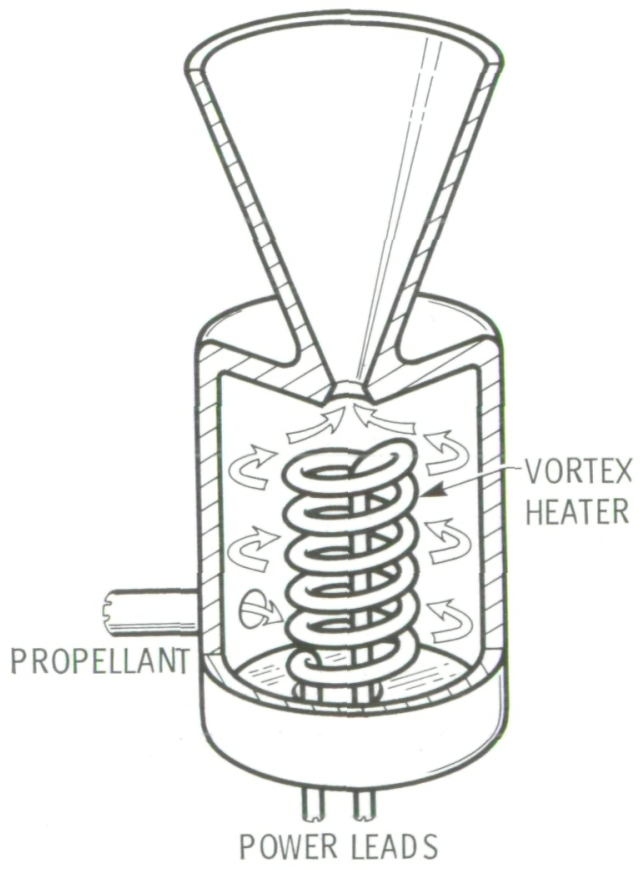

(a) HiPEHT type.

Figure 12. - Resistojet heat exchangers. 


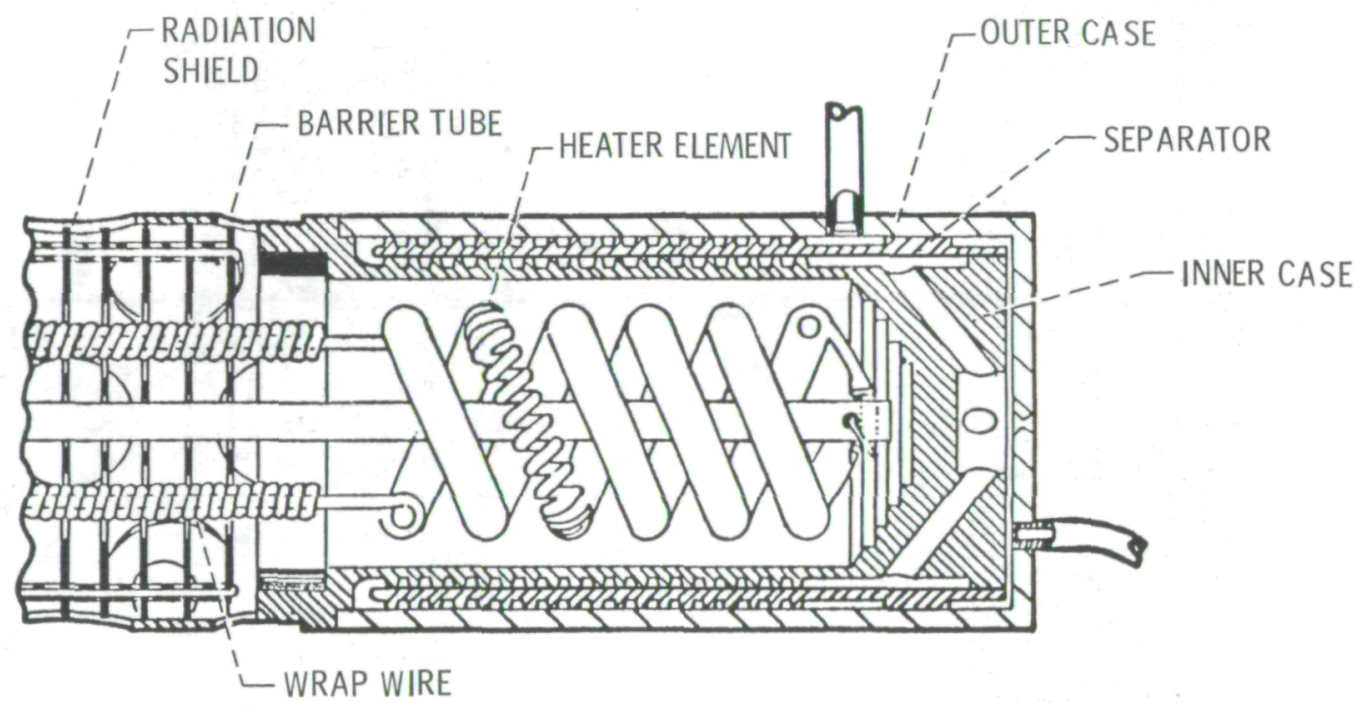

(b) A. C. T. type.

Figure 12. - Concluded. 

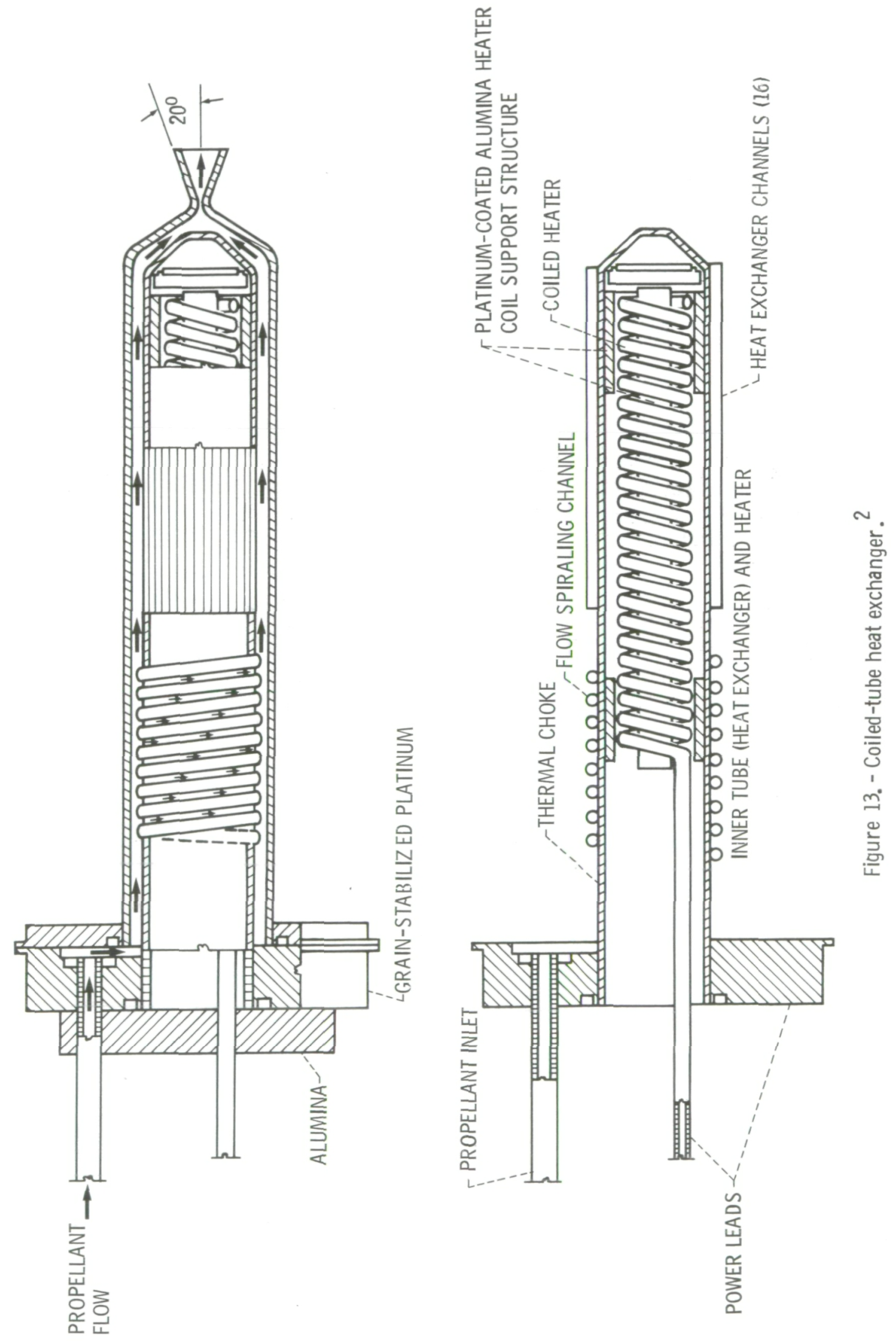


\section{$\left(A_{\text {EXIT }} / A_{\text {THROAT }}=100.0\right.$, REY $\left.=1000.0\right)$}

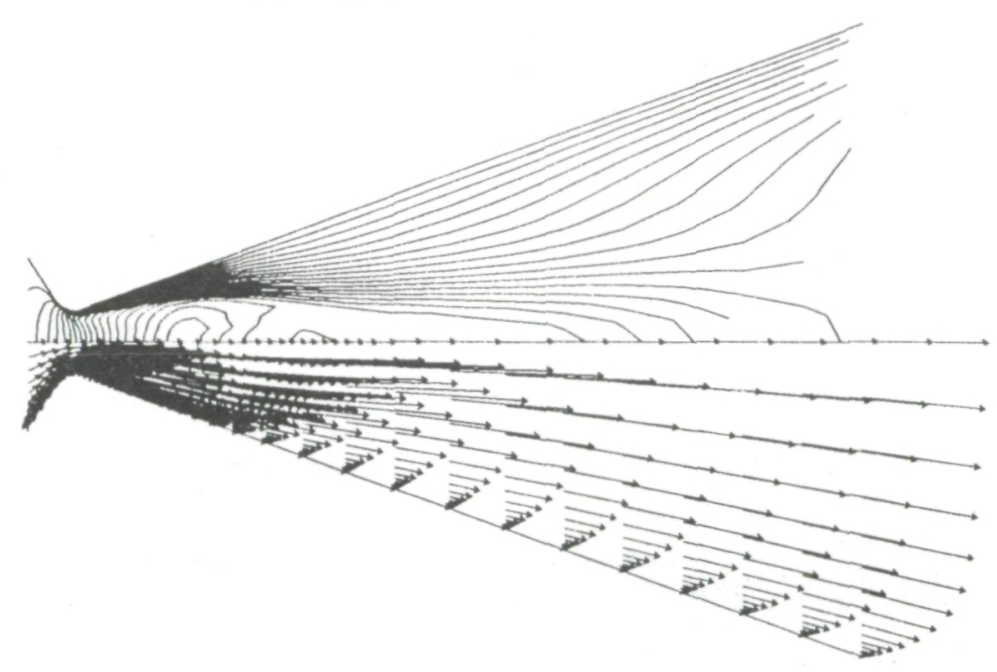

Figure 14. - Space vectoring nozzle. ${ }^{10}$

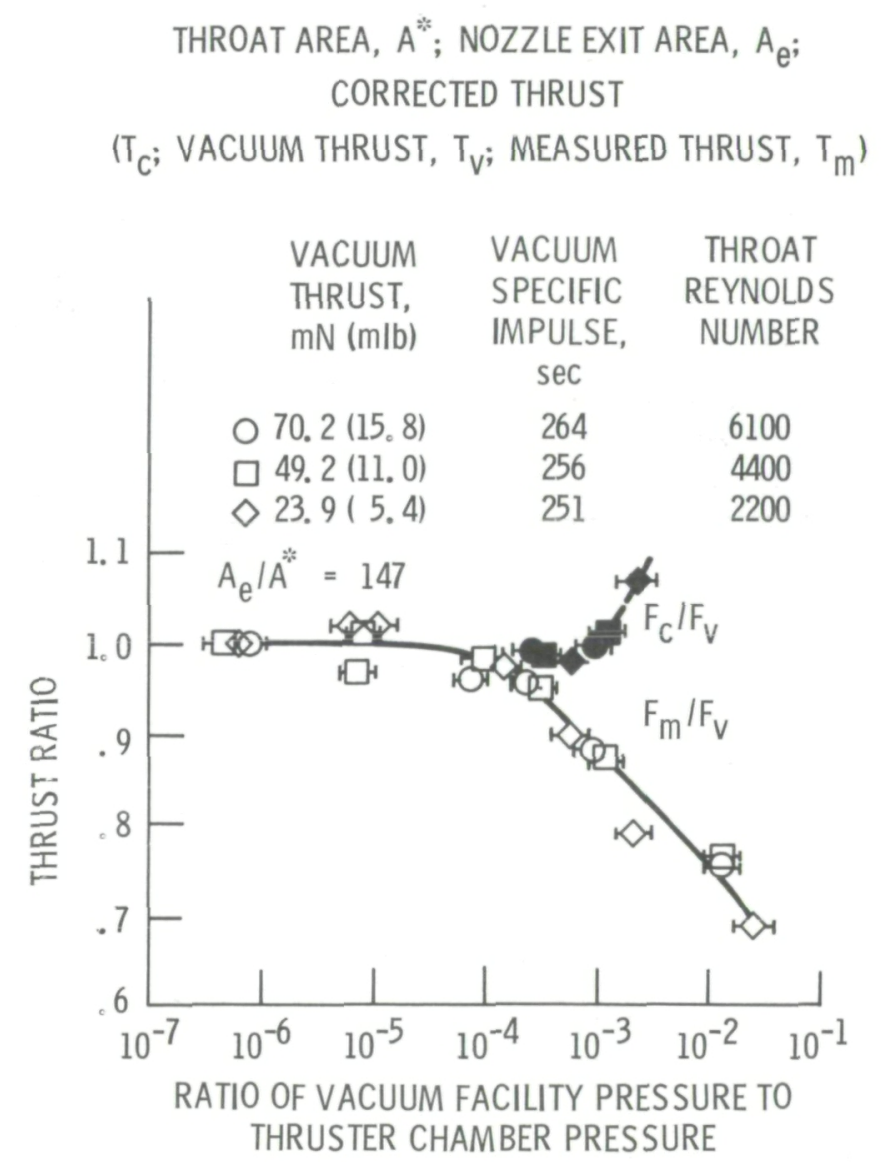

Figure 15. - Thrust versus vacuum facility pressure, unheated hydrogen. ${ }^{9}$ 


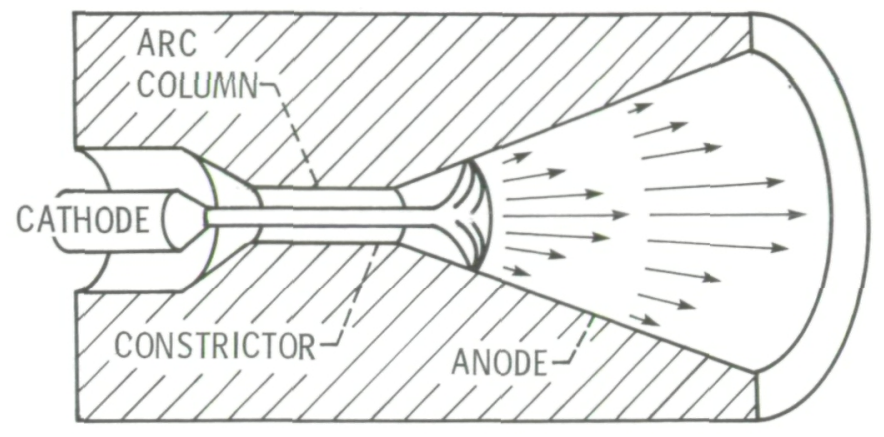

(a) Conventional design .

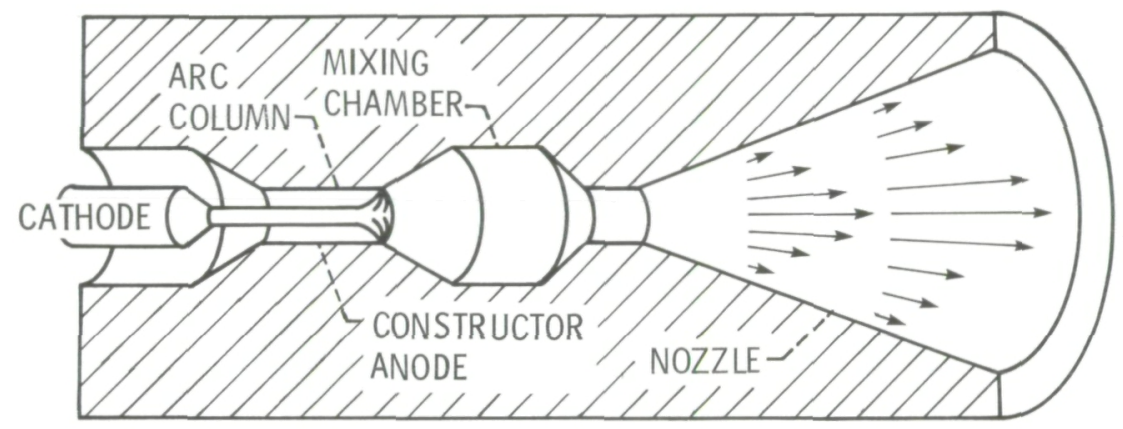

(b) Mixing chamber concept.

Figure 16。 - Arcjet schematics.
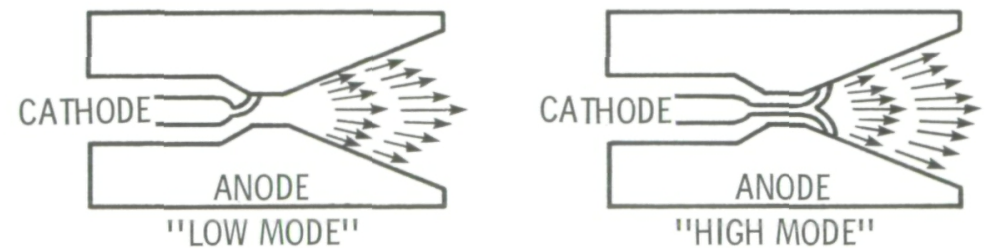

"HIGH MODE"

- constricted aRC SPOT

- RAPIDLY VARYING CHARACTERISTICS

- DIFFUSE ANODE ATTACHMENT

- dESTRUCTIVE

- STABLE ARC CHARACTERISTICS

- NON-DESTRUCTIVE

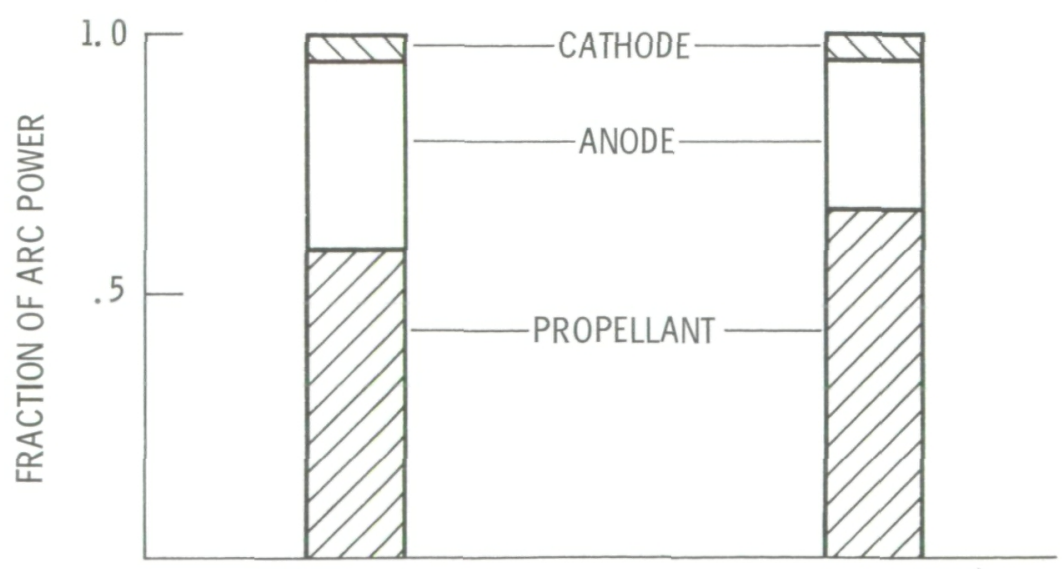

Figure 17. - Fundamental modes of arc-jet operation. 


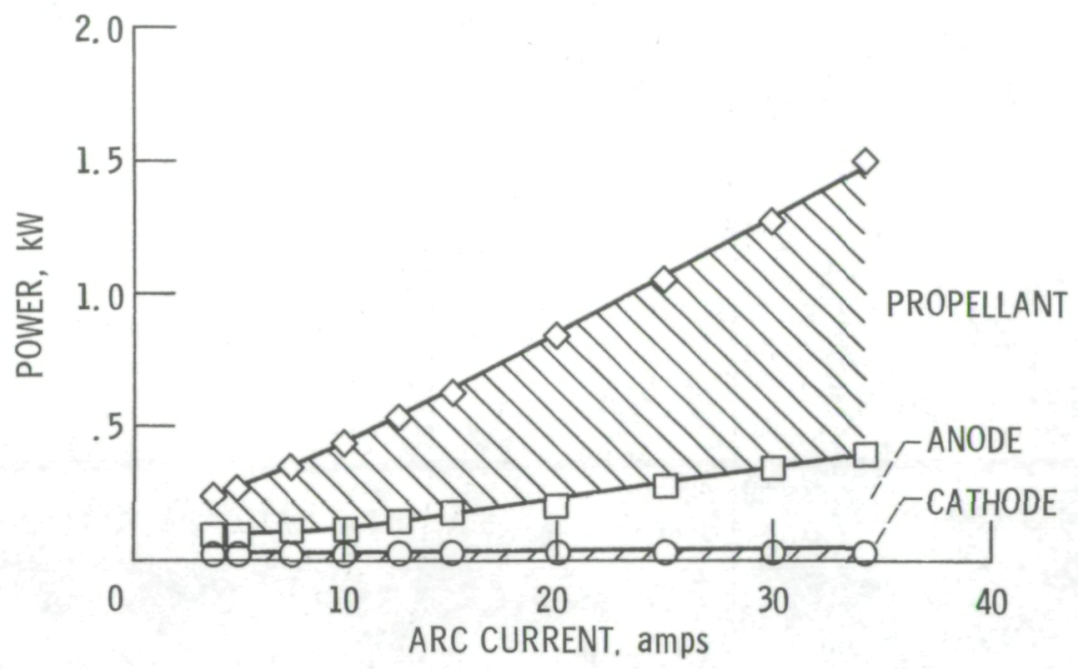

Figure 18. - Typical energy distribution in arcjet. 12

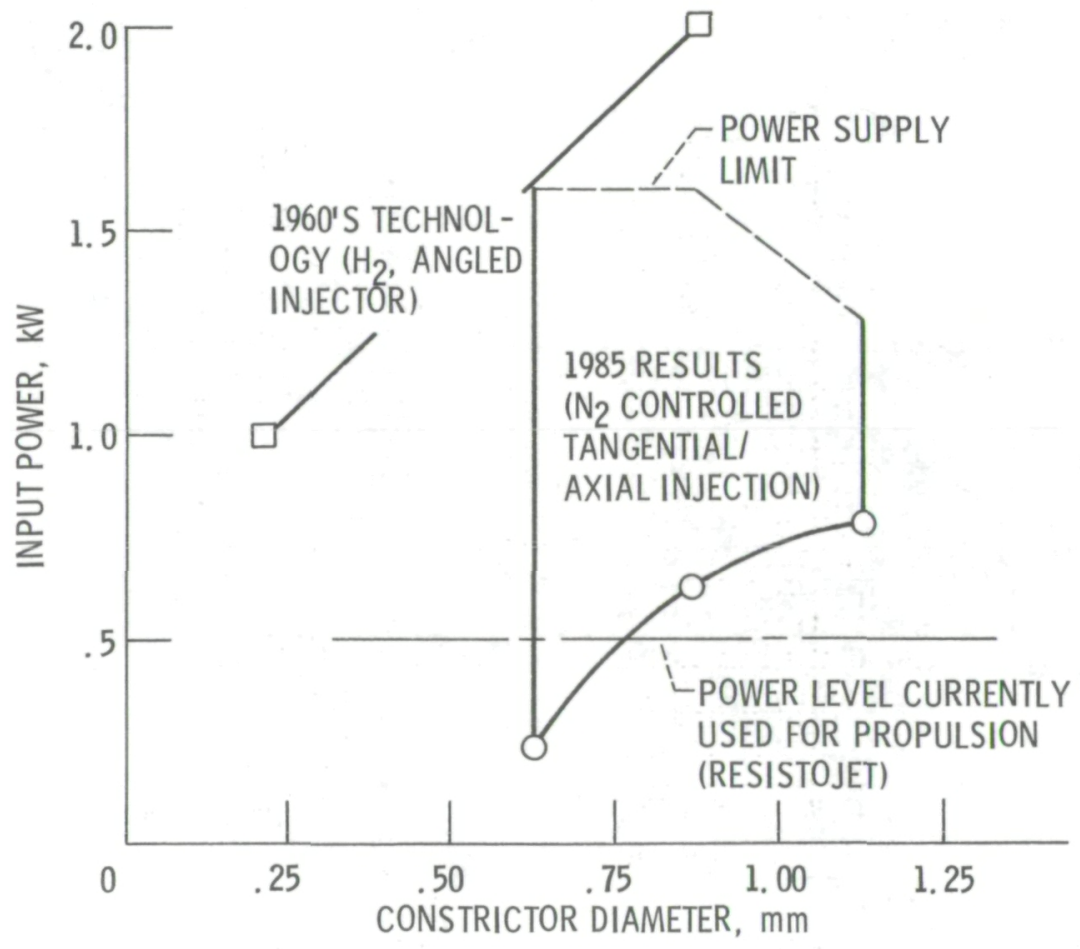

Figure 19. - Extended stable operating range. 


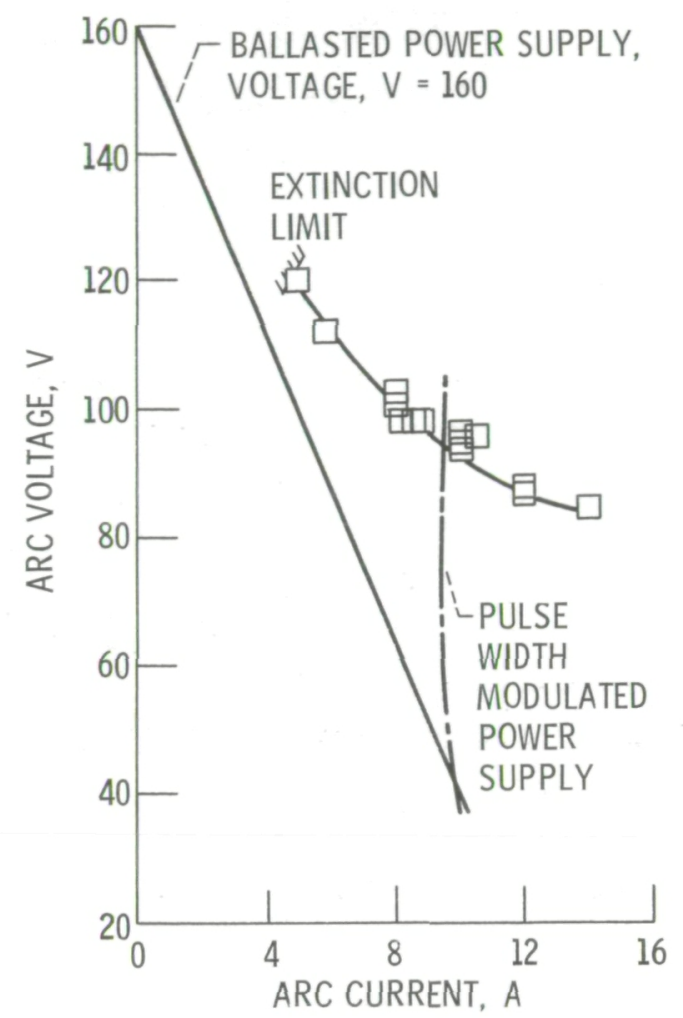

Figure 20. - Typical arcjet voltagecurrent characteristics. ${ }^{13}$ Simulated hydrazine, $\dot{\mathrm{m}}=3.1 \mathrm{mg} / \mathrm{sec}$.

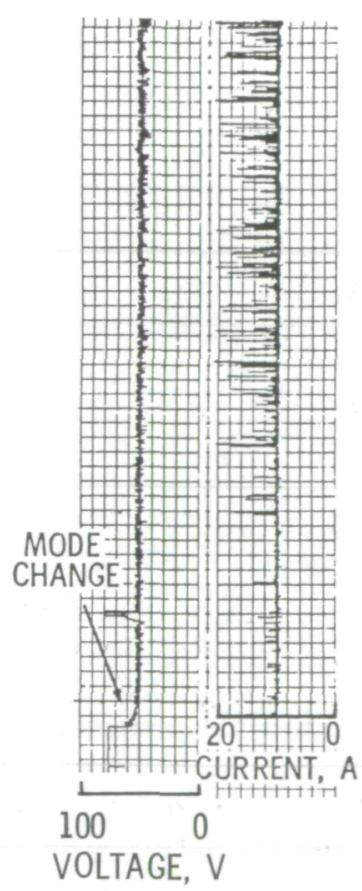

(a) Ballasted lab supply.power source.

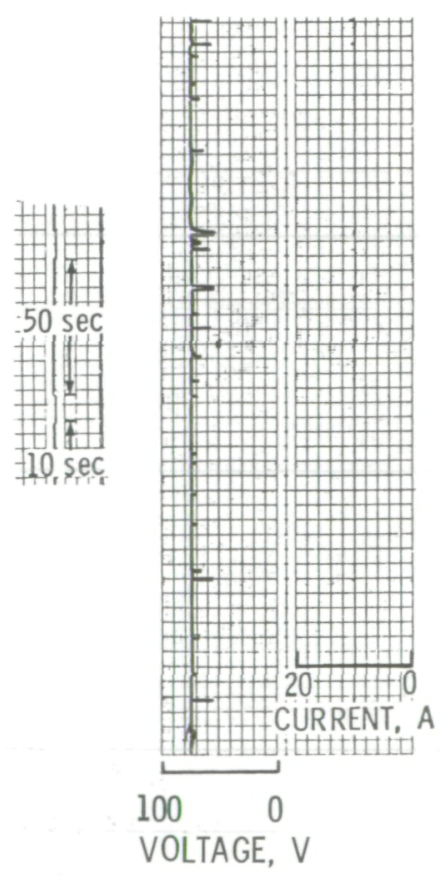

(b) Fast response PWM current regulator.

Figure 21. - Influence of power supply on arcjet operation. 13,16 


\section{ORIGINAL PAGE IS OF. POOR QUALITY}

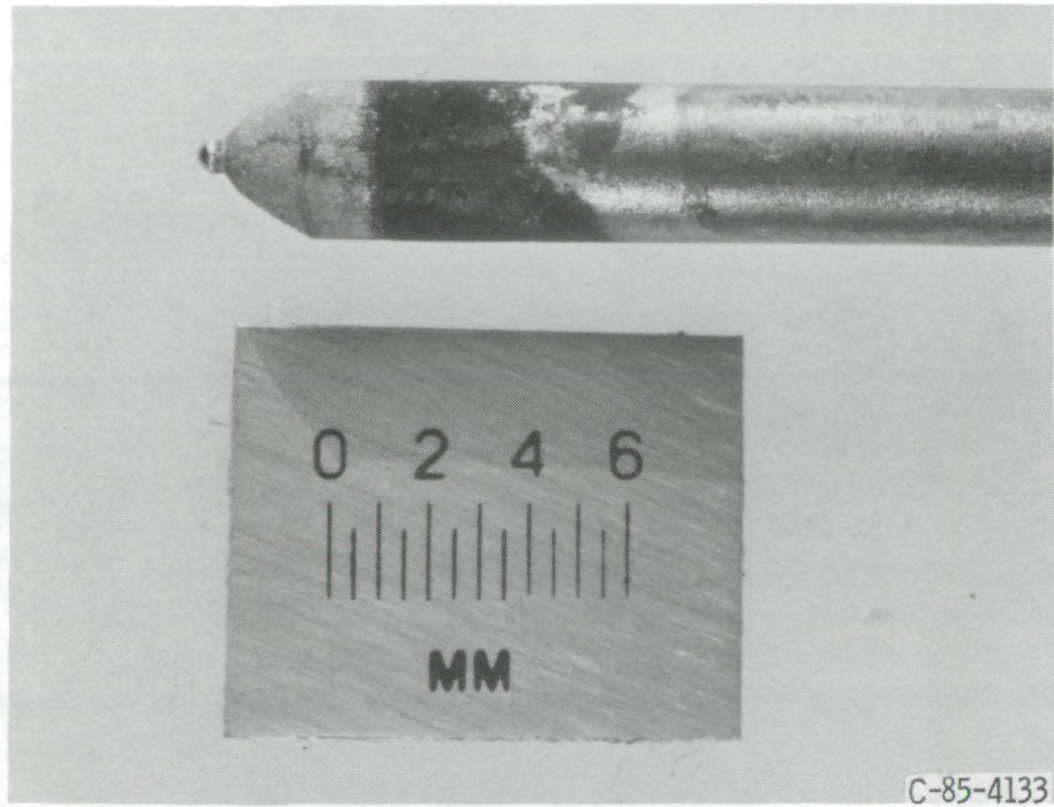

(a) Hard starting, unstable operation.

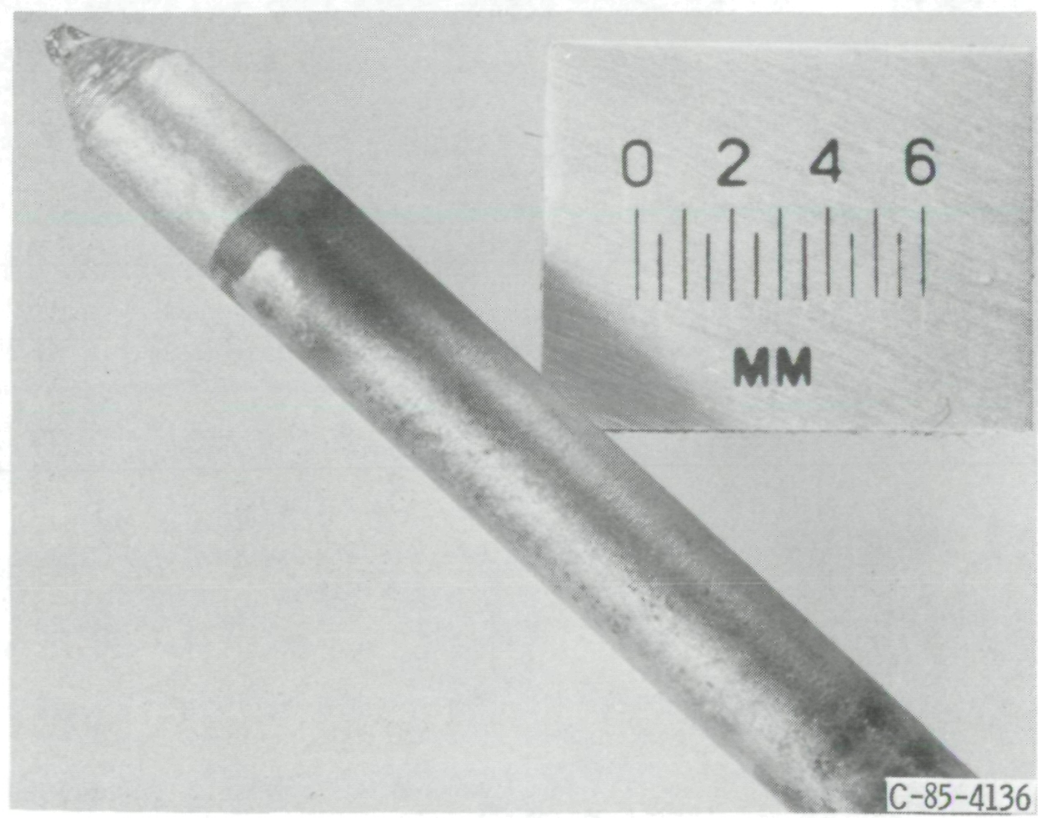

(b) Soft starting, stable operation.

Figure 22. - Effect of starting techniques and stability on cathode condition 12 . 


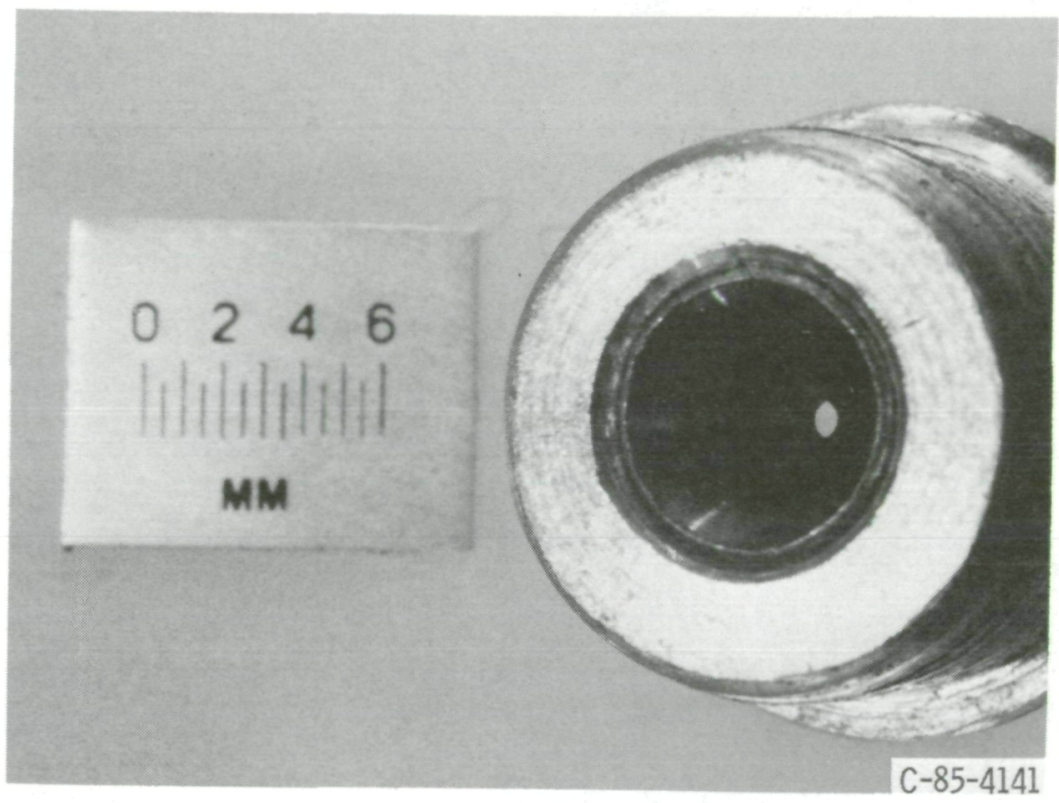

(a) Stable operation, soft starting.

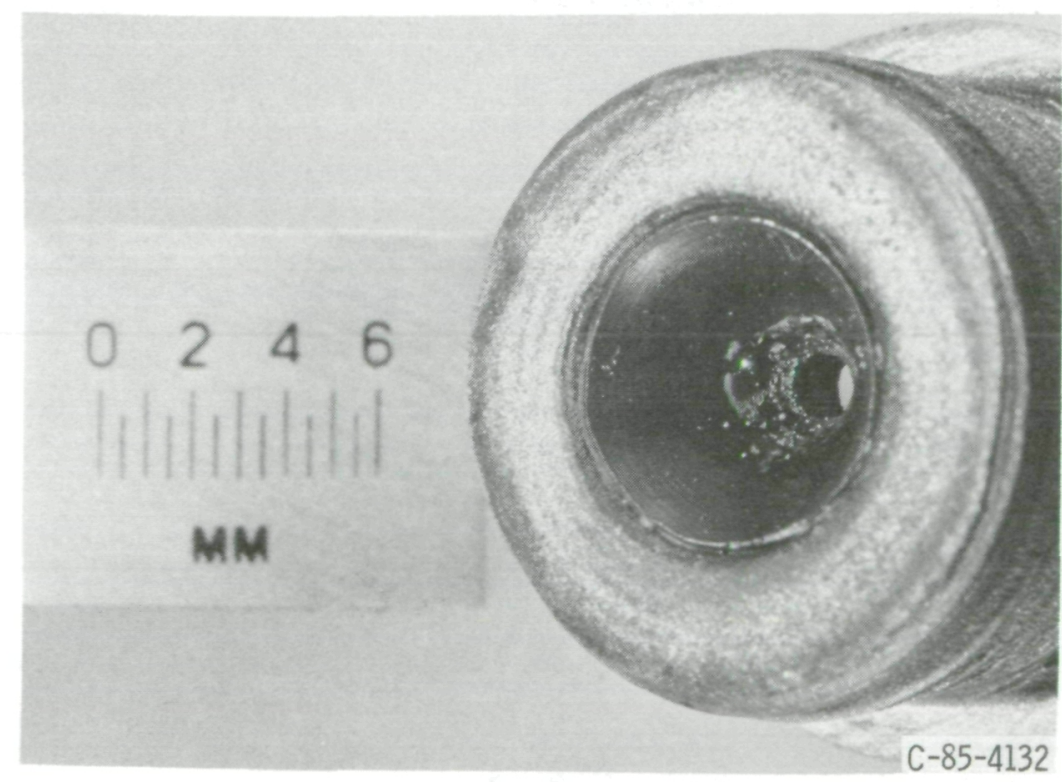

(b) Unstable operation, hard starting.

Figure 23. - Effect of starting techniques and stability on anode condition ${ }^{12}$. 


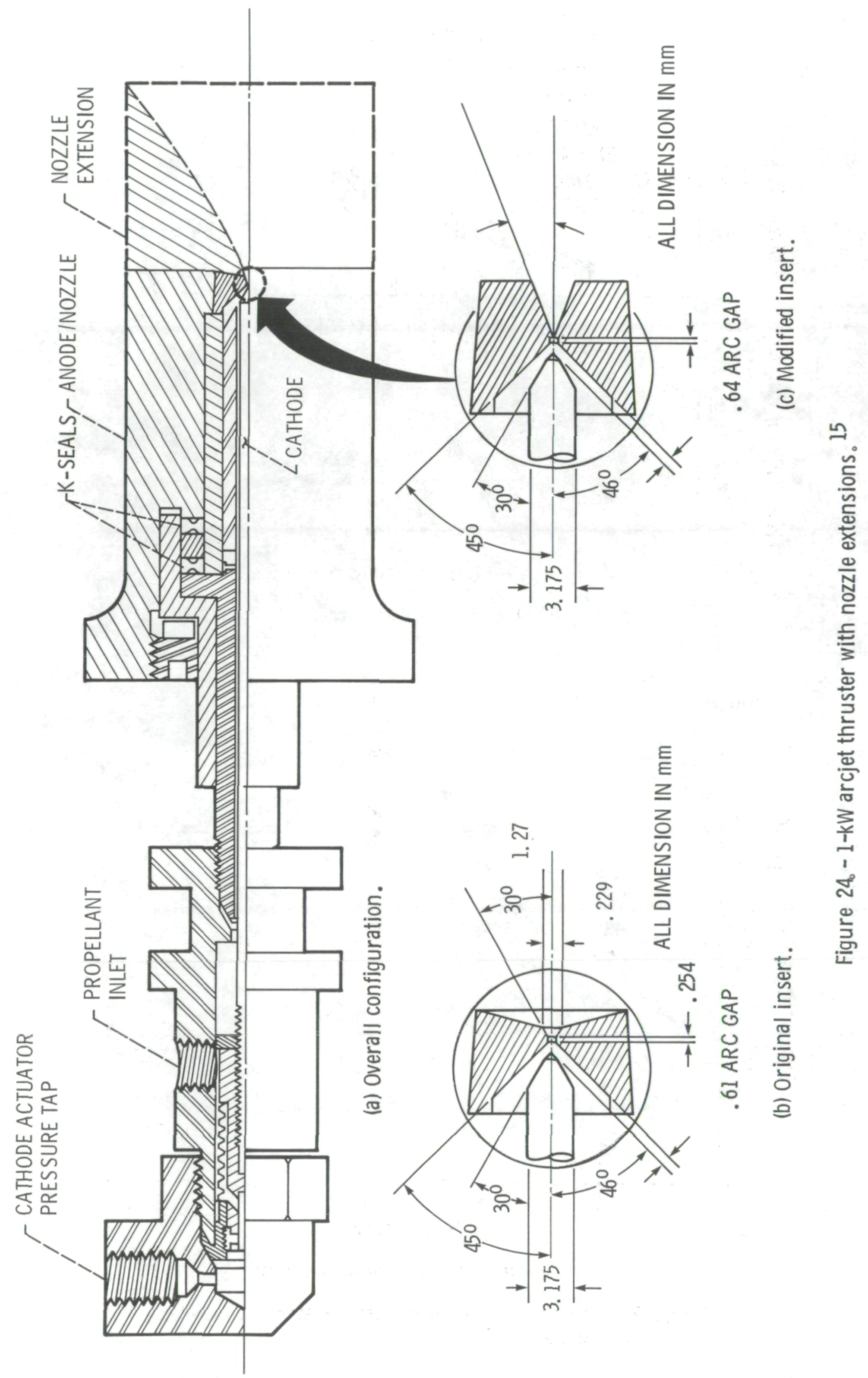



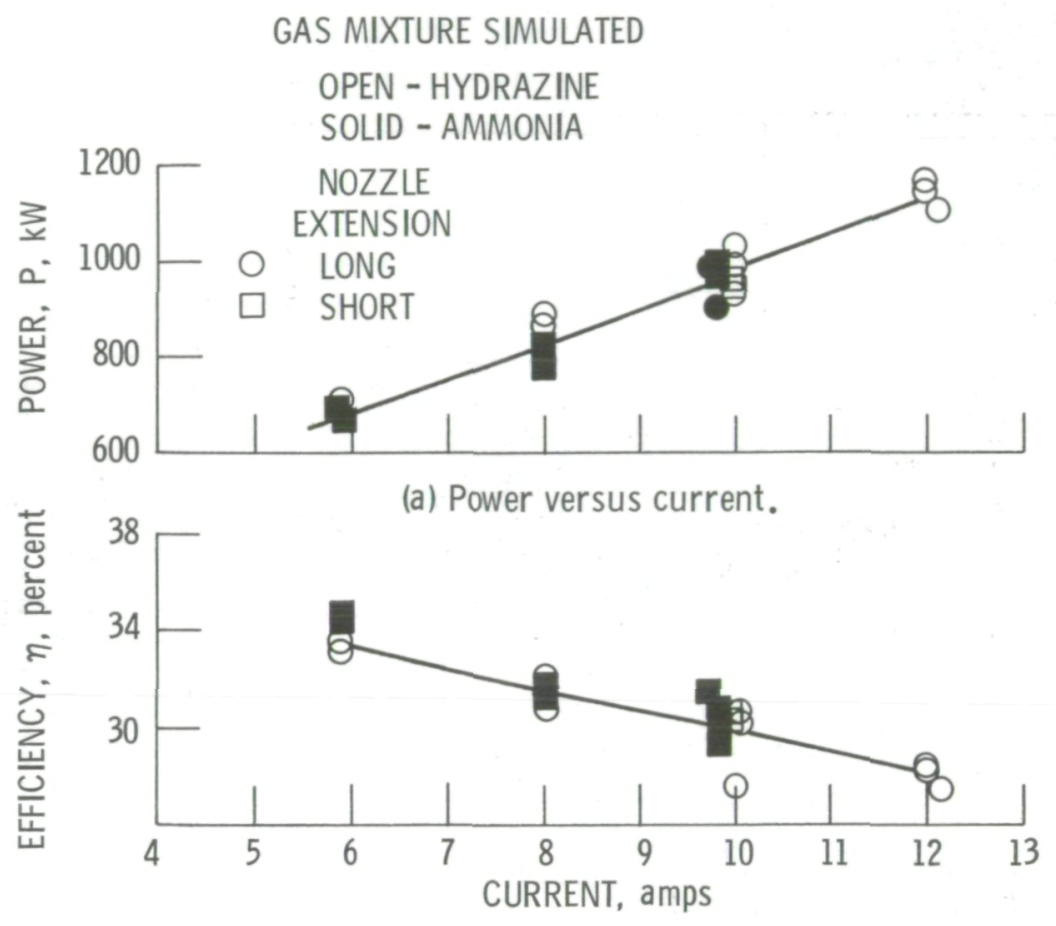

(b) Efficiency versus current.

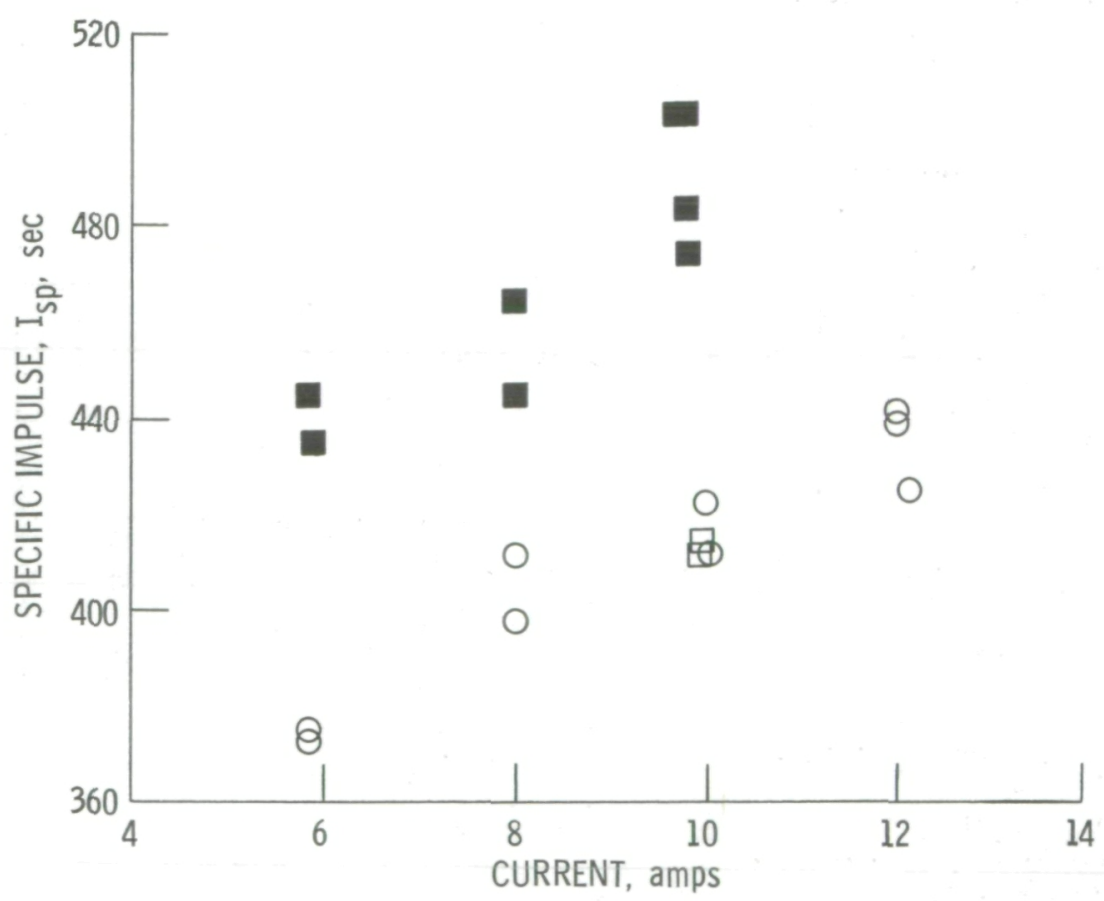

(c) Specific impulse, versus current.

Figure 25. - Performance of $1-\mathrm{kW}$ class arcjet with simulated storable propellants. 15 


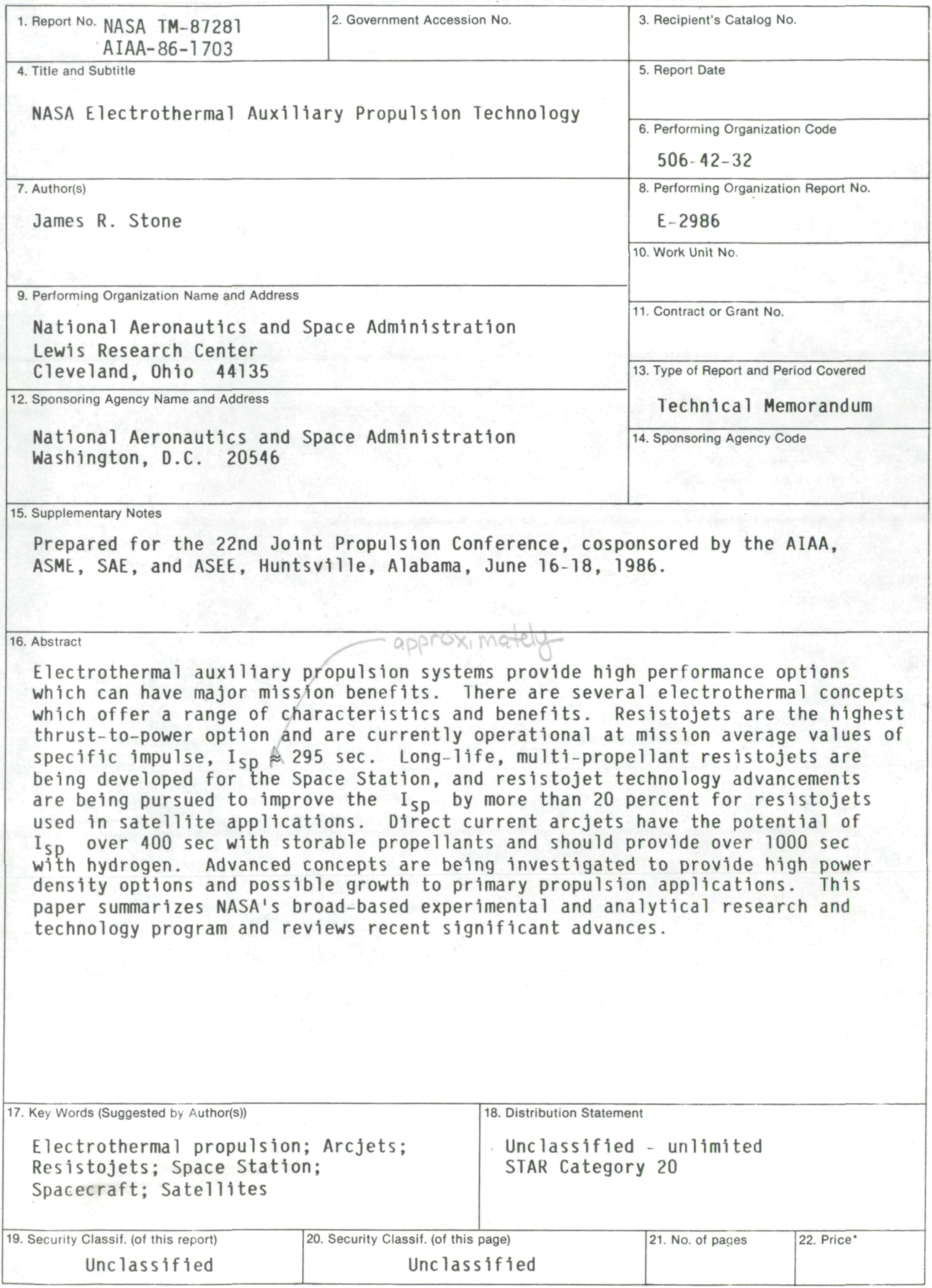

${ }^{*}$ For sale by the National Technical Information Service, Springfield, Virginia 22161 
National Aeronautics and

Space Administration

Lewis Research Center

Cleveland. Ohio 44135

Official Business

Penalty for Private Use $\$ \mathbf{3 0 0}$
SECOND CLASS MAIL

ADDRESS CORRECTION REQUESTED

National Aeronautics and

Space Administration NASA-451 